This PDF is a selection from a published volume from the National Bureau of Economic Research

Volume Title: NBER Macroeconomics Annual 2004, Volume 19

Volume Author/Editor: Mark Gertler and Kenneth Rogoff, editors

Volume Publisher: MIT Press

Volume ISBN: 0-262-07263-7

Volume URL: http://www.nber.org/books/gert05-1

Publication Date: April 2005

Title: The Business Cycle and the Life Cycle

Author: Paul Gomme, Richard Rogerson, Peter Rupert, Randall Wright

URL: http://www.nber.org/chapters/c6673 


\title{
The Business Cycle and the Life Cycle
}

\author{
Paul Gomme, Richard \\ Rogerson, Peter Rupert, and \\ Randall Wright \\ University of Iowa and Federal \\ Reserve Bank of Cleveland; \\ Arizona State University and \\ NBER; University of Western \\ Ontario and Federal Reserve \\ Bank of Cleveland; and \\ University of Pennsylvania \\ and NBER
}

\section{Introduction}

The representative household model is the workhorse of modern business-cycle theory. One can understand this from several perspectives. First, from an empirical perspective, the business cycle is defined in terms of time series variation in the per-capita values for several key aggregate variables. By construction, the representative agent model is a model of per-capita values. Second, from a conceptual perspective, the process of understanding is facilitated by first analyzing economic forces in simple settings, and abstracting from heterogeneity helps to maintain simplicity in the model. Third, from a technical perspective, the appropriate theoretical framework in modern business-cycle theory is dynamic stochastic general equilibrium theory, and the assumption of a representative agent greatly reduces the burden of such analysis, both computationally and theoretically.

These factors suggest that representative agent models are a useful starting point for analyzing the economic forces that shape aggregate fluctuations. However, the thesis of this paper is that our understanding of labor market fluctuations (in particular) will be enhanced by moving beyond the representative agent model. The essence of our argument follows from a simple empirical finding. As we document, the magnitude of business-cycle fluctuations in hours of market work varies quite significantly across subgroups in the population. We believe that understanding why some groups fluctuate more than others should be relevant for understanding why the aggregate fluctuates as 
much as it does. Consider two scenarios. In the first, suppose that for reasonable parameterizations, a given model is unable to account for a sizable fraction of observed fluctuations in aggregate hours. In assessing which modifications to the theory may be most relevant, it would be important to know if the problem was that the model systematically underaccounts for fluctuations in hours across all groups, or if the problem is that it cannot account for the magnitude of fluctuations experienced by some specific groups. In the second scenario, suppose that for reasonable parameterizations, a given model is able to account for the bulk of aggregate fluctuations in hours. While this is useful information, we would obviously be more confident that the economic forces captured in this model are indeed the relevant ones if they were also able to account for the patterns of fluctuations across various groups.

In this paper, we pursue a disaggregated analysis of fluctuations in market work by considering one specific dimension of heterogeneityage. Specifically, we document how cyclical fluctuations in hours of market work vary over the life cycle, and then assess the predictions of a life-cycle version of the growth model for the observations. Our analysis yields a simple but striking finding. The main discrepancy between the model and the data lies in the inability of the model to account for fluctuations in hours for individuals over the first half of their life cycle; it can account for most of the fluctuations for individuals aged 45-64 without resorting to extreme labor supply elasticities. This suggests that in looking for alternative theories to account for aggregate labor market fluctuations, attention should be directed toward features that specifically affect individuals during the first half of their lives. Although the goal of this paper is not to present alternatives to the benchmark life-cycle growth model, one is led to think about the options: e.g., to ask whether search frictions, say, as opposed to sticky wage models or other candidates, may be more relevant in terms of affecting workers differently at different stages of the life cycle. ${ }^{1}$ In this sense, our goal is to raise some issues without trying to resolve everything here.

While heterogeneity has received a lot of recent attention in macroeconomics, it is important to distinguish our emphasis from that of others. A recurring issue in many studies is whether introducing a particular type of heterogeneity, often in connection with some other feature, will influence the properties of the aggregate time series. In these studies, the emphasis remains on the properties of the aggregate vari- 
ables and not on the behavior of disaggregated series. One example of this is Krusell and Smith (1998), who ask whether a model with idiosyncratic income shocks and incomplete markets would produce different aggregate responses to technology shocks. Another example is Rios-Rull (1996), who studies a similar model to the one used here, but whose main objective is to see if aggregate fluctuations are different in an overlapping generations model than in the standard infinitely lived agent model. Both of these studies concluded that the properties of aggregate fluctuations were not much affected. In contrast, our goal is to ask whether allowing for heterogeneity provides more insight into the details of a particular shock and propagation mechanism by explicitly focusing on the implications of the model for fluctuations at the disaggregated level. $^{2}$

Though our work is related to several papers in the literature, two papers are particularly relevant. The first is Clark and Summers (1981), who documented that cyclical fluctuations in employment vary across demographic groups, and the second is Rios-Rull (1996), who examined fluctuations in a life-cycle economy. Our empirical work extends Clark and Summers along several important dimensions. Specifically, we analyze additional dimensions of heterogeneity, use more conventional methods to define cyclical components, examine both the intensive and extensive margins, and perform additional robustness checks. While our results for fluctuations by age are similar to theirs, we find differences along other dimensions. Our theoretical work also extends the work of Rios-Rull along several dimensions. Specifically, we consider a different class of preferences, our model allows for home production and life-cycle preference shifters, and we assume a different market structure. Most important, however, we carry out a detailed analysis of the role that various factors play in shaping the volatility of hours over the life cycle.

Although we do not pursue it here, we believe that the life-cycle model developed and analyzed in this work is of independent interest in other contexts as well. For example, it would allow one to study how fluctuations in cohort size affect economic outcomes. Shimer (1998), for example, argued empirically that fluctuations in cohort size had a large impact on fluctuations in aggregate unemployment.

The rest of the paper is organized as follows. In Section 2, we describe a standard representative household (infinitely lived agent) model and examine its predictions concerning fluctuations in aggregate hours. Section 3 documents the extent to which the cyclical variation in 
hours varies with several household characteristics. Section 4 presents and calibrates our version of the growth model populated by overlapping generations. Section 5 presents the results of the model concerning business-cycle fluctuations, with a particular focus on its implications for fluctuations in hours by age. Section 6 is devoted to discussing the factors that give rise to the observed pattern of fluctuations. Section 7 presents some international evidence on fluctuations in hours worked by age, and Section 8 concludes.

\section{A Representative Agent Model}

For purposes of comparison, it is instructive to start with a representative agent model of the sort that serves as one of the benchmark models of business-cycle analysis. Rather than formulating the model in its most general form, we restrict attention to a specification with commonly used functional forms. We add two features relative to the simplest possible specification: household production and a government sector. We include household production because previous work has shown that models with household production do a much better job of accounting for several aspects of business cycles, particularly for hours of market work. ${ }^{3}$ We include a government sector because taxes are an important element in calibrating home and market capital stocks.

\subsection{Model}

There is an infinitely lived representative household with preferences:

$$
\sum_{t=0}^{\infty} \beta^{t}\left[\log C_{t}-\frac{\omega}{\gamma} H_{t}^{\gamma}\right]
$$

where $\beta \in(0,1)$ is the discount factor, $C_{t}$ is a constant elasticity of substitution (CES) aggregator of market and home consumption in period $t$, and $H_{t}$ is total time spent working in the market and at home in period $t$. That is,

$$
\begin{aligned}
& C_{t}=\left[\psi C_{m t}^{\xi}+(1-\psi) C_{n t}^{\xi}\right]^{1 / \xi} \\
& H_{t}=H_{m t}+H_{n t}
\end{aligned}
$$

where $C_{m t}$ and $C_{n t}$ are market and home consumption, respectively, and $H_{m t}$ and $H_{n t}$ are market and home work, respectively. The agent is endowed with one unit of time each period and $K_{0}$ units of capital at 
$t=0$. The parameters $\gamma \geq 1$ and $\xi \leq 1$ play a key role in influencing the business-cycle predictions of the model since $\gamma$ determines the substitutability in hours worked across time, and $\xi \leq 1$ determines the extent of substitutability between home and market goods. As a result, these parameters dictate the amount of intertemporal and intratemporal substitution in hours of market work.

We choose the utility function $\log C-(\omega / \gamma) H_{t}^{\gamma}$ to facilitate comparison with the large literature in labor economics that tries to estimate $\gamma$. The standard life-cycle labor literature (without home production) typically assumes separability in the sense that $U\left(C_{t}, H_{t}\right)=u\left(C_{t}\right)+v\left(H_{t}\right)$. In a deterministic setting, this means that the first-order condition for $h_{t}$ can be written as:

$v^{\prime}\left(H_{t}\right)=-w_{t} \lambda$

where $\lambda$ is the Lagrange multiplier on the lifetime budget constraint and $w_{t}$ is the wage in period $t$. Due to separability, this condition does not include $C_{t}$, so one can take the equation to the data without having to observe consumption. If $v(H)=-(\omega / \gamma) H^{\gamma}$, then (after taking logs and rearranging) we have:

$\log \left(H_{t}\right)=\alpha_{0}+\frac{1}{\gamma-1} \log \left(w_{t}\right)$

where $\alpha_{0}$ can incorporate a constant, a time trend, and an error term, depending on assumptions. From this, one can estimate the elasticity $1 /(\gamma-1)$ and recover the structural parameter $\gamma^{4}$

The above analysis does not require specifying $u(C)$. It is well-known in macro, however, that balanced growth requires either $U(C, H)=$ $C^{\sigma} v(H)$ or $U(C, H)=\log (C)+v(H)$ for some function $v(H)$. Hence, assuming separability so that we can apply the labor supply results, we are led to:

$u(C, H)=\log (C)+v(H)$

for some function $v(H)$. Although in principle any function $v(H)$ satisfying the usual regularity conditions would do, we will adopt the common specification $v(H)=-(\omega / \gamma) H^{\gamma}$.

Incorporating home production into the analysis now merely requires reinterpreting $C$ and $H$ as composites of market and home consumption and of market and home work: $C=C\left(C_{M}, C_{H}\right)$ and $H=H\left(H_{M}, H_{H}\right)$. Here, we follow much of the previous literature by assuming $C=\left[\psi C_{m}^{\xi}+(1-\psi) C_{n}^{\xi}\right]^{1 / \xi}$, so that we can appeal to existing 
estimates of the parameter $\xi$, and $H=H_{m}+H_{n}$, which means hours worked in the market and home are perfect substitutes. The last thing to say about preference is that, although there will be a government in the model, we assume that agents derive no utility from government consumption. ${ }^{5}$

In terms of technology, there is a production function:

$$
Y_{m t}=z_{\mathrm{f}} K_{m t}^{\theta}\left[(1+g)^{t} H_{m t}\right]^{1-\theta}
$$

where $Y_{m t}$ is market output in period $t ; K_{m t}$ and $H_{m t}$ are capital and labor services, respectively, used in market production in period $t ; z_{t}$ is a technology shock; and $g$ represents the constant rate of labor augmenting technological change. We assume that $z_{t}$ follows the process:

$\log z_{t+1}=\rho \log z_{t}+\varepsilon_{t+1}$

where $\varepsilon_{t}$ is an independently and identically distributed (iid) random variable that is normally distributed with mean $\mu_{m}$ and variance $\sigma_{m}^{2}$. The period $t$ realization of $\varepsilon$ is observed before any decisions are made. Market output produced in period $t$ can be used either as market consumption $C_{m l}$, government consumption $G_{t}$, or investment $I_{t}$ :

$C_{m t}+G_{t}+I_{t}=Y_{m t}$

There is also a production function for home produced goods:

$Y_{n t}=K_{n t}^{\eta}\left[(1+g)^{t} H_{n t}\right]^{1-\eta}$

where $Y_{n t}$ is household production in period $t ; K_{n t}$ and $H_{n t}$ are capital and labor services, respectively, used in home production in period $t$; and $g$ again represents the constant rate of labor augmenting technological change. We assume the same rate of technological change in the two production functions, as is required for balanced growth. Although we assume the home production function is CobbDouglas, following Greenwood and Hercowitz (1991), some authors have argued that departures from Cobb-Douglas are crucial for understanding certain issues, including the pattern of investments in home and market capital. The estimates in McGrattan et al. (1997) imply the home production function is significantly different from CobbDouglas (the model actually allows both market and home production functions to be CES, but the estimates implied only the latter is significantly different from Cobb-Douglas). For the issues on which we focus, however, this does not matter much, so we use Cobb-Douglas 
for simplicity. We also abstract from shocks to the home production function since they will not play any role in the subsequent analysis. ${ }^{6}$

One asymmetry between market and home production is that the only use of home-produced output is as home consumption, i.e.:

$C_{n t}=Y_{n t}$

That is, although capital is used in home production, it is produced only in the market sector. Capital accumulation is given by:

$K_{m t+1}=\left(1-\delta_{m}\right) K_{m t}+I_{m t}$

$K_{n t+1}=\left(1-\delta_{n}\right) K_{n t}+I_{n t}$

where $I_{m t}$ and $I_{n t}$ are investment in market and home capital, respectively, in period $t$, and both are constrained to be nonnegative, while $\delta_{m} \in(0,1)$ and $\delta_{n} \in(0,1)$ are depreciation rates. Aggregate investment in period $t$ is the sum of investment in home and market capital: ${ }^{7}$

$I_{t}=I_{m t}+I_{n t}$

It is well known that empirically plausible tax rates can have big effects in this model. Since we will be choosing some parameter values by calibrating to steady-state values, it is important to incorporate taxes into the specification. Given that our primary reason for doing so is to facilitate calibration, however, we assume constant tax rates. In particular, we assume that market labor income is taxed at the constant rate $\tau_{h}$, and capital income is taxed at the constant rate $\tau_{k}$. The government uses tax revenues to finance spending $G_{t}$, which we assume is a constant ratio of market output. The government faces a periodby-period budget constraint, with lump-sum transfers $\tau_{t}$ serving to achieve budget balance.

\subsection{Parameterization}

Calibration of parameter values for this model is fairly standard. Because of this, and also because we will go into detail on the calibration of the overlapping generations model later in the paper, we do not provide details here and simply report the parameter values in Table 1. Note that we set a period to be a year in this paper. While it is more common in infinitely lived agent models to use a quarter rather than a year, the basic properties of the model are not affected by this choice. We will be using an annual model once we introduce overlapping 
Table 1

Parameters for infinitely-lived household calibration

\begin{tabular}{llllllllll}
\hline$\beta$ & $\theta$ & $\eta$ & $\delta_{m}$ & $\delta_{n}$ & 8 & $\rho$ & $\sigma_{\delta}$ & $\tau_{h}$ & $\tau_{k}$ \\
\hline .954 & .30 & .27 & .065 & .057 & .018 & .806 & .0139 & .25 & .50 \\
\hline
\end{tabular}

generations because the data on hours worked by age is at annual frequency. Not shown in Table 1 is that we assume government spending relative to market output to be 20 .

There are also four utility parameters not listed in Table 1: the elasticity parameters $\gamma$ and $\xi$, and the coefficients giving weights on market versus home consumption and on hours versus total consumption, $\psi$ and $\omega$. The standard procedure for determining values for these parameters is to set $\omega$ and $\psi$ so that the steady-state values of $H_{m}$ and $H_{n}$ are equal to some target values taken from the data, typically $H_{m}=\frac{1}{3}$ and $H_{n}=\frac{1}{4}$, and to set $\gamma$ and $\xi$ in accord with the empirical literature because they cannot be pinned down easily by steady-state considerations. It is well known that the values of the two elasticity parameters $\gamma$ and $\xi$ matter a lot for the cyclical properties of hours. There is also considerable controversy over these parameters, and estimates can vary a lot depending on which group one looks at (e.g., males versus females), which features are incorporated (e.g., skill accumulation, home production), and which margins one considers (e.g., the intensive versus the extensive margin). Hence, we will present results for a wide range of values for $\gamma$ and $\xi$, without necessarily taking a stand on any particular value.

\subsection{Results}

It is well known that models of this sort can mimic the broad features of cyclical fluctuations in the U.S. economy, although the magnitude of fluctuations in market hours has received considerable attention since the model does less well on this (see Hansen and Wright, 1992). In particular, we will emphasize the relative standard deviation of market hours to market output. ${ }^{8}$ In the data, the relevant number is .80 , which is the standard deviation of market hours based on current population survey (CPS) data over the period 1962-2000, relative to the standard deviation of output over this same period. The standard deviation of hours is 1.79 and the standard deviation of output is 2.23, where these numbers are annual and correspond to data that has been 
Table 2

Standard deviation of market hours relative to output

\begin{tabular}{lllllll}
\hline & $\gamma=1$ & $\gamma=2$ & $\gamma=2.5$ & $\gamma=3.0$ & $\gamma=4$ & $\gamma=11$ \\
\hline$\xi=0$ & .66 & .48 & .45 & .43 & .40 & .35 \\
$\xi=.2$ & .67 & .50 & .47 & .45 & .43 & .38 \\
$\xi=.4$ & .68 & .53 & .51 & .49 & .47 & .44 \\
$\xi=.5$ & .69 & .56 & .54 & .52 & .50 & .47 \\
$\xi=.6$ & .71 & .59 & .57 & .56 & .54 & .52 \\
$\xi=.8$ & .78 & .71 & .70 & .69 & .69 & .68 \\
\hline
\end{tabular}

Hodrick-Prescott (HP)-filtered with a smoothing parameter of 100 . We note that our output measure excludes the service flow from housing since we treat this as a nonmarket service.

Given the calibration strategy discussed above, Table 2 reports values for the standard deviation of market work relative to market output (both HP-filtered) that come from simulating the model. We generate samples that are 39 periods in length, the same as our data, and average over 1000 runs. Table 2 reports the results for values of $\gamma$ ranging from 1 to 11, which corresponds to elasticities ranging from infinite to .1 , and values of $\xi$ ranging from 0 to .8 , which corresponds to elasticities ranging from 1 to 5 . As can be seen, and as is fairly well known, the model can account for most of the fluctuations in market hours if (and only if) the elasticities are sufficiently large. Perhaps somewhat less well known is that it is not sufficient to know the value of the intertemporal elasticity parameter $\gamma$ to assess the model on this dimension since even if $\gamma$ is set to 11 , the model would still be able to account for the bulk of the observed fluctuations if the value of $\xi$ were sufficiently high. ${ }^{9}$

There is considerable debate over the appropriate value of $\gamma$ for the representative household, and even less is known about the parameter $\xi$. This notwithstanding, just to fix ideas, suppose we use values in the upper part of the plausible range, in particular, $\gamma=2.5$ and $\xi=.5$, corresponding to elasticities of $\frac{2}{3}$ and 2 , respectively. The implied relative standard deviation of hours is equal to .54 , roughly two-thirds of what we observe in the data. This suggests that although the model accounts for a substantial fraction of the volatility in market hours, there is also a sizable fraction that it misses.

One is then naturally led to consider modifications to the model to better match the behavior of market hours. Many such modifications 
have been proposed in the literature, including alternative specifications of preferences (e.g., Kydland and Prescott, 1982), search frictions (e.g., Merz, 1995; Andolfatto, 1996; and Den Haan, Ramey, and Watson, 2000), informational asymmetries (e.g., Gomme, 1999, and Alexopoulos, 2004), restrictions on working hours (e.g., Rogerson, 1988, and Hansen, 1985), alternative formulations of technology (e.g., Kydland and Prescott, 1988), and alternative wage-setting mechanisms (e.g., Danthine and Donaldson, 1995). What we want to argue in the remainder of this paper is that if we are looking for ways to isolate the key empirical deficiencies of equilibrium macro models like the one described above, we ought to consider a lower level of aggregation. In the next section, we document a wide range in variability of market hours over the business cycle across subgroups. In view of this, it seems interesting to ask whether the mechanism implicit in the model underaccounts for fluctuations across all subgroups, or if perhaps it does account for the fluctuations of some groups but not others. Put somewhat differently, if we are trying to understand the causes of fluctuations in hours of work over the business cycle, it seems reasonable that understanding why some groups fluctuate much more than other groups would be a key piece of information.

\section{Beyond Aggregate Data}

In this section, we document differences in the magnitude of cyclical fluctuations in market hours across groups in the population. In particular, we disaggregate by age, education, marital status, gender, and industry of employment.

\subsection{Fluctuations by Age}

Using data from the March Supplement of the CPS for the period 1962-2000, we compute aggregate market hours per capita for the entire population aged 16 and above, and market hours per capita by age for seven age groups: 16-19, 20-24, 25-34, 35-44, 45-54, 55-64, and $65+$. The standard procedure for defining the business-cycle component of an aggregate series is the percentage deviation from a suitably defined trend, defined here using the HP filter. To extract the component of fluctuations in aggregate hours that is accounted for by each age group, we use a two-step procedure described in the appendix (Section 9). The results are in Table 3. 
Table 3

Relative cyclical fluctuations of hours by age group

\begin{tabular}{lccccccc}
\hline & $16-19$ & $20-24$ & $25-34$ & $35-44$ & $45-54$ & $55-64$ & $65+$ \\
\hline$\sigma_{h} / \sigma_{\gamma_{m}}$ & 2.23 & 1.23 & .86 & .64 & .57 & .59 & 1.26 \\
$\%$ of $H_{m}$ & 4 & 11 & 26 & 25 & 20 & 12 & 2 \\
$\%$ of $\sigma_{H_{m}}$ & 11 & 16 & 28 & 19 & 14 & 9 & 3 \\
\hline
\end{tabular}

Table 4

Fluctuations of sectoral hours relative to GDP

\begin{tabular}{lllllllll}
\hline \multirow{2}{*}{ Sector } & Agr & Min & Cons & Mfg & Trans & Tr & FIRE & Serv \\
\hline$\sigma_{h} / \sigma_{Y_{\text {In }}}$ & 1.44 & 1.69 & 2.17 & 1.24 & .75 & .80 & .55 & .57 \\
\hline
\end{tabular}

The first row shows fluctuations in the hours of each age group relative to output. The second row indicates the fraction of average hours worked by each age group over the entire sample period. The third row indicates the fraction of fluctuations accounted for by each age group. Several interesting patterns emerge. First, note that the pattern of fluctuations across age groups is $U$-shaped: fluctuations are highest for young and old workers, and are lowest for middle-aged workers. Related to this, the second and third rows indicate the extent to which cyclical fluctuations in hours are disproportionately accounted for by fluctuations in the hours of work of younger workers. Workers aged 16-24 account for only $15 \%$ of total market hours, but more than $25 \%$ of fluctuations in market hours. Conversely, prime-age workers, between the ages of 35 and 54 , account for $45 \%$ of total market hours but for only $33 \%$ of fluctuations in market hours. ${ }^{10}$

One may be concerned that the patterns displayed above are not due to age effects per se but are really an artifact of a situation in which workers of different ages work at different jobs, with some jobs being more cyclically volatile than others. To explore this possibility, we examine the role that the age distribution of hours worked across onedigit industries may play in shaping fluctuations by age group. Table 4 shows the relative volatility of hours of work across one-digit sectors. As is well known, hours in some sectors fluctuate much more over the business cycle. In particular, goods-producing sectors display more volatility than do service sectors. Table 5 indicates the distribution of hours worked by each age group across each of these eight sectors. 
Table 5

Sectoral distribution of hours by age

\begin{tabular}{lrrrrrrr}
\hline & $16-19$ & $20-24$ & $25-34$ & $35-44$ & $45-54$ & $55-64$ & $65+$ \\
\hline Agr & 5.17 & 2.99 & 2.91 & 3.20 & 3.81 & .01 & 12.89 \\
Min & .45 & .92 & 1.08 & 1.06 & .98 & .90 & .43 \\
Cons & 4.59 & 6.26 & 6.81 & 6.56 & 5.87 & 5.91 & 3.66 \\
Mfg & 15.78 & 22.34 & 23.82 & 24.23 & 24.78 & 25.07 & 11.04 \\
Trans & 2.97 & 5.94 & 7.86 & 8.62 & 8.35 & 7.70 & 3.59 \\
Wh/Re Tr & 44.30 & 26.10 & 19.52 & 17.98 & 18.30 & 20.43 & 22.47 \\
FIRE & 4.43 & 7.13 & 6.93 & 6.38 & 6.21 & 6.52 & 7.55 \\
Ser & 22.32 & 28.33 & 31.08 & 31.97 & 31.70 & 33.46 & 38.37 \\
\hline
\end{tabular}

Table 6

Relative fluctuations induced by sectoral composition

\begin{tabular}{llllllll}
\hline Age & $16-19$ & $20-24$ & $25-34$ & $35-44$ & $45-54$ & $55-64$ & $65+$ \\
\hline$\sigma_{h_{m}} / \sigma_{Y_{m t}}$ & .81 & .83 & .84 & .84 & .84 & .81 & .79 \\
\hline
\end{tabular}

Table 5 reveals that there are indeed some sharp differences across age groups in how their hours of work are distributed across sectors. For example, the distribution of hours in the manufacturing sector is increasing in age up until 65. Hours of work of teenagers are heavily skewed toward the wholesale and retail trade sector. Mining, construction, and transportation and public utilities all display an inverted Ushape across age groups, whereas wholesale and retail trade displays a U-shape across age groups. Given that each age group has a distinctive pattern of hours across sectors and that fluctuations vary across sectors, we can ask how fluctuations would vary by age if the only source of differences by age were the sectoral distribution of hours. The answer is given in Table 6, where we take a weighted average of the sectoral relative volatilities for each group using the age distribution of hours across sectors as weights.

Two observations emerge from this exercise. First, the size of the effects induced by differences in sectoral composition across age groups is small-the range of values goes only from .79 to .84 . We conclude from this finding that abstracting from sectoral composition effects is a reasonable thing to do. Second, to the extent that sectoral composition effects do matter, they actually generate an inverted $U$ for the pattern of volatility across age, the opposite of what we see in the 
data. It follows that the pattern in Table 3 would be even more pronounced if we controlled for sectoral composition.

Given previous research on the importance of the intensive and extensive margins of labor hours adjustment, it is also of interest to see if there is any systematic difference across groups in the importance of the two margins. However, analysis revealed this not to be the case. We found that the percentage of total fluctuations accounted for by the extensive margin varied within the relatively narrow range of $68-$ $72 \%$.

To close this subsection, recall the discussion of the infinitely lived representative agent model in the previous section. We suggested that an empirically plausible parameterization generates relative fluctuations in hours of work equal to .54. Recall also the first row of Table 3, which showed the relative volatility of hours by age. Looking at this row with the number .54 in mind raises a key issue. One interpretation of these findings is that the previous model is actually successful in accounting for the fluctuations of hours of prime-age individuals, and that its main shortcoming is accounting for the fluctuations in hours of younger workers. Of course, this interpretation is not warranted in the infinitely lived representative agent framework; we need to consider a model in which agents differ by age. We pursue exactly this in the remaining sections of this paper. Before we do so, however, we think it is also of interest to examine the heterogeneity in hours fluctuations along some additional dimensions.

\subsection{Fluctuations by Education}

Here, we repeat the previous analysis, but this time we split the population by education. Because we do not model fluctuations by educational attainment in our theoretical analysis below, we do not carry out as extensive an analysis of this case as we did for age. Also, due to data issues, we restrict our attention to the years 1974-2000. And because measuring educational attainment for young workers is difficult, we restrict our attention to individuals age 25 or greater. For each year, using the March CPS, we compute hours per person for individuals in four educational groups: (1) those with less than high school, (2) those with exactly high school, (3) those with some college but no college degree, and (4) those with at least a college degree. Again, we extract the component of fluctuations in aggregate hours accounted for by each of these groups. 
Table 7

Hours fluctuations by education, 1974-2000

\begin{tabular}{lllll}
\hline & $<\mathrm{HS}$ & $\mathrm{HS}$ & $\mathrm{SC}$ & $\mathrm{C}$ \\
\hline$\sigma_{h_{m}} / \sigma_{Y_{m}}$ & 1.20 & .84 & .67 & .23 \\
\hline
\end{tabular}

Table 8

Hours fluctuations by gender, 1962-2000

\begin{tabular}{lll}
\hline & Males & Females \\
\hline$\sigma_{h_{m}} / \sigma_{Y_{m}}$ & .87 & .73 \\
\hline
\end{tabular}

The results are reported in Table 7, which raises a similar issue to the one in the previous subsection: is it possible that the model does a good job of explaining fluctuations for those with, say, at least some college education, and that the model's shortcomings are entirely to do with the fluctuations in the other groups? Although we will not address this question explicitly in this paper, we believe that understanding the sources of these differences in volatility across education groups may also help us better understand the fluctuations in the aggregate data.

\subsection{Fluctuations by Gender and Marital Status}

In the model that we study below, we will continue to take the unit of analysis to be a household, and we will assume the sole dimension along which households differ is age. In particular, we will abstract from differences in household size, and we will abstract from the issue of time allocations across household members in multimember households. We still think it is interesting, however, to examine the extent to which fluctuations in market hours differ along the dimensions of marital status and gender (if for no other reason, this helps in assessing the extent to which our abstractions are warranted). Using the same procedure as above, we extract the component of aggregate hours fluctuations that is accounted for first by men and women, and then by married and unmarried individuals. For these series, the data cover the period 1962-2000.

Table 8 reports relative fluctuations for men and women. Somewhat surprisingly, men display larger cyclical fluctuations than do women. One may suspect that part of this difference is accounted for by sec- 
Table 9

Hours fluctuations by gender and sector $\left(\sigma_{h_{m}} / \sigma_{Y_{m}}\right), 1962-2000$

\begin{tabular}{lllllllll}
\hline & Agr & Min & Cons & Mfg & Tran & Re Tr & FIRE & Ser \\
\hline Males & 1.49 & 1.64 & 1.99 & 1.09 & .72 & .70 & .61 & .63 \\
Females & 1.46 & 2.28 & 1.51 & 1.27 & .68 & .83 & .47 & .52 \\
\hline
\end{tabular}

Table 10

Relative standard deviation of hours by age and gender $\left(\sigma_{h_{m}} / \sigma_{Y_{m}}\right), 1962-2000$

\begin{tabular}{llllllll}
\hline & $16-19$ & $20-24$ & $25-34$ & $35-44$ & $45-54$ & $55-64$ & $65+$ \\
\hline Male & 2.60 & 1.52 & .96 & .64 & .60 & .73 & 1.16 \\
Female & 2.01 & 1.00 & .75 & .69 & .55 & .45 & 1.50 \\
\hline
\end{tabular}

Table 11

Standard deviation of hours by marital status and age, 1962-2000

\begin{tabular}{llllllll}
\hline & $16-19$ & $20-24$ & $25-34$ & $35-44$ & $45-54$ & $55-64$ & $65+$ \\
\hline Marrled & 1.98 & 1.03 & .79 & .61 & .52 & .61 & 1.19 \\
Not Married & 2.35 & 1.36 & 1.07 & .80 & .87 & .61 & 1.47 \\
\hline
\end{tabular}

toral composition patterns. Table 9 shows that this is indeed a factor. This table shows that in several sectors, notably manufacturing and wholesale and retail trade, males display less volatility than do females.

It is also of interest to examine how the variability across the life cycle varies by gender. In Table 10 , we report relative variability by age, using the same procedure as before. Table 10 shows the pattern of volatility over the life cycle is $\mathrm{U}$-shaped for both males and females, though the timing of the trough is different across the groups-for men, the volatility begins to increase in the 55-64 group, whereas for women, it does not increase until the $65+$ group. Quantitatively there are some differences-for younger workers, the volatility of hours is somewhat less for females, while for individuals aged 35-44, the volatility is somewhat higher for females. Taken together, we interpret these findings with respect to gender as supporting our decision to abstract from the within-family decision in the analysis that follows. ${ }^{11}$

Table 11 reports the results disaggregated by marital status, where we note that fluctuations here are at the individual level and not at the household level. Fluctuations for single individuals are significantly larger than they are for married individuals. It is important to keep in 
mind that among prime-age individuals, the majority are married, so that for these individuals, the aggregate numbers look very similar to those of the married group. For younger groups, however, the reverse is true. Here again, note that the basic pattern is U-shaped for both groups, with the exception of the observation for the 45-54 group that is not married. For this group, however, the majority of fluctuations in hours are not correlated with movements in aggregate hours, so this number does not necessarily reflect the overall fluctuations for this group. We conclude from Table 11 that there are indeed differences across married and unmarried individuals. If we interpret our model as applying to married households, it follows that the target levels of volatility are somewhat lower as a result.

\section{A Life-Cycle Model}

In the remainder of the paper, we focus on the nature of fluctuations by age. The obvious way to incorporate this type of heterogeneity into the model is to move from the infinitely lived representative agent framework to the overlapping generations framework. The goal will be to retain the basic structure of the infinitely lived household model as much as possible, while introducing life-cycle considerations. To maintain simplicity, some of these considerations will be captured in somewhat of a reduced form manner-for example, rather than explicitly modeling fertility, we will simply assume that preference parameters change systematically over the life cycle.

\subsection{Model}

In each period, a representative $T$-period lived household is born. We abstract from population growth and assume that length of life is deterministic, although one could extend things on these dimensions at some cost in terms of simplicity. In our quantitative analysis, we interpret a period to be a year and set $T=55$, and we think of a household beginning economic decisionmaking at age 20 and continuing until 75. We impose exogenously that agents retire at age $T_{R}$. Agents have preferences over lifetime profiles of consumption and work. For a generic variable $s$, we will use $s_{t}^{a}$ to denote the value of $s$ for an agent of age $a$ in period $t$, and we use lowercase (uppercase) letters to represent choices at the individual (aggregate) level. Hence, for an agent born in period $t$, preferences are given by: 


$$
\sum_{a=0}^{T-1} \beta^{a} U\left(c_{m, t+a}^{a+1}, c_{n, t+a}^{a+1}, h_{m, t+a}^{a+1}, h_{n, t+a}^{a+1}, \psi^{a}, \omega^{a}\right)
$$

where $c_{m}^{a}$ is market consumption, $c_{n}^{a}$ is household consumption, $h_{m}^{a}$ is market work, and $h_{n}^{a}$ is home work at age $a$, while $\psi^{a}$ and $\omega^{a}$ are lifecycle preference shifters. $^{12}$

We make the same assumption regarding functional forms as earlier. In particular, the period utility function $U\left(c_{m}^{a}, c_{n}^{a}, h_{m}^{a}, h_{n}^{a}, \psi^{a}, \omega^{a}\right)$ is of the form:

$$
U=\left[\psi^{a}\left(c_{m}^{a}\right)^{\xi}+\left(1-\psi^{a}\right)\left(c_{n}^{a}\right)^{\xi}\right]^{1 / \xi}-\frac{\omega^{a}}{\gamma}\left(h_{m}^{a}+h_{n}^{a}\right)^{\gamma}
$$

Each household is endowed with one unit of time in each period of life, which can again be allocated among three uses: working in the market, working at home, and enjoying leisure. As in the previous model, agents derive no utility from government consumption.

An important empirical regularity is that wages exhibit significant changes over the life cycle. We incorporate this feature by assuming that the efficiency units corresponding to a given amount of time spent working changes with age. In particular, each unit of time spent in market work at age $a$ yields $e^{a}$ efficiency units of market labor input. ${ }^{13}$ We could also assume that each unit of time spent in home work at age $a$ yields $e_{n}^{a}$ efficiency units of household labor input. However, given the life-cycle preference shifter $\psi^{a}$, there is really nothing to be gained by this, so we assume $e_{n}^{a}$ does not vary with $a .^{14}$

As before, we assume that home-produced goods are nontraded and can be used only as consumption. Hence, for a household of age $a$ at time $t$, we have:

$c_{n t}^{a}=\left(k_{n t}^{a}\right)^{\eta}\left[(1+g)^{t} h_{n t}^{a}\right]^{1-\eta}$

where $k_{n t}^{a}$ is the stock of home capital for a household of age $a$ in period $t, h_{n t}^{a}$ is time spent in home production by a household of age $a$ in period $t$, and we assume that the rate of technological progress is the same in both production functions to have balanced growth.

The laws of motion for individual stocks of capital satisfy:

$k_{m t+1}^{a+1}=\left(1-\delta_{m}\right) k_{m t}^{a}+i_{m t}^{a}$

$k_{n t+1}^{a+1}=\left(1-\delta_{n}\right) k_{n t}^{a}+i_{n t}^{a}$

while the aggregate laws of motion for the capital stocks are given by: 


$$
\begin{aligned}
& K_{m t+1}=\left(1-\delta_{m}\right) K_{m t}+I_{m t} \\
& K_{n t+1}=\left(1-\delta_{n}\right) K_{n t}+I_{n t}
\end{aligned}
$$

We assume that each household begins economic life with an endowment of home capital $k_{n 0}$; that is, $k_{n t}^{1}=k_{n 0}$ for all $t$. Without this endowment, agents would have no home capital in the first period of their life, which gives rise to big differences in the time allocated to home work in the first and all other periods of life. For internal consistency, we assume that this endowment of home capital is transferred from the age $T$ cohort to the newborn cohort each period; i.e., we require that individuals make choices such that $k_{t n}^{T+1}=k_{n 0}$. Aside from this, we assume no links between the generations.

As above, the government consumes $G$ and finances expenditures via proportional taxes $\tau_{h}$ and $\tau_{k}$ that do not vary over time, balancing the budget every period by adjusting the lump-sum transfer $\tau_{t}$. Given that the total mass of households alive at any date is $T$, and letting $w_{t}$ and $r_{t}$ denote the wage per efficiency unit of labor and the rental rate of market capital, respectively, this implies:

$\tau_{t}=\left(\tau_{h} w_{t} E_{m t}+\tau_{k} r_{t} K_{m t}-G_{t}\right) / T$

where $E_{m t}$ is the aggregate supply of labor measured in efficiency units.

Individual budget constraints are given by:

$c_{m t}^{i}+i_{m t}^{i}+i_{n t}^{i}=\left(1-\tau_{h}\right) w_{t} e^{a} h_{m t}^{a}+\left(1-\tau_{k}\right) r_{t} k_{m t}^{a}+\tau_{t}$

We require that $k_{n t}^{a}$ is always nonnegative. By contrast, although aggregate market capital cannot be negative, we assume that individuals may hold negative market capital $k_{m t}^{a}$ as a way to borrow. We do not place any explicit restriction on the extent to which individuals can borrow, but we do require that everyone have zero holdings of market capital at the time of death, $k_{m t}^{T+1}=0$. In a deterministic model, these restrictions implicitly generate a maximum feasible debt at each age. In a stochastic model, the situation is more complicated, but in practice, we found that this issue is irrelevant in the quantitative analysis since the shocks are not that large. Hence, we impose no explicit restrictions on holdings of market capital.

The market technology is given by:

$Y_{m t}=z_{t} K_{m t}^{\theta}\left[(1+g)^{t} E_{m t}\right]^{1-\theta}$ 
where $K_{m t}$ is the input of market capital, $E_{m t}$ is the input of market labor measured in efficiency units, $g$ is the constant rate of labor augmenting technological progress, and $z_{t}$ is an aggregate shock that follows exactly the same process as in the representative agent model. Aggregate efficiency units of market labor are given by:

$$
E_{m t}=\sum_{a=1}^{T} e^{a} h_{m t}^{a}
$$

Market output in period $t$ has four uses: private market consumption $C_{m t}$, government consumption $G_{t}$, investment in market capital $I_{m t}$, and investment in home capital $I_{n t}$. Hence feasibility requires:

$C_{m t}+G_{t}+I_{m t}+I_{n t} \leq Y_{m t}$

where

$C_{m t}=\sum_{a=1}^{T} c_{m t}^{a}, \quad I_{m t}=\sum_{a=1}^{T} i_{m t}^{a}, \quad$ and $\quad I_{n t}=\sum_{a=1}^{T} i_{n t}^{a}$

We abstract from any form of public social security and do not allow markets for risk sharing. Note that in this model, all shocks are aggregate shocks, which induce changes in wages and rental rates, but all individuals face the same wage per efficiency unit of labor. In principle, once one allows for heterogeneity, there is the possibility of the shocks affecting individuals differently even if they are perfectly correlated. It is possible, for example, that fluctuations in market hours differ across groups because the size of the shocks differ across groups. Our formulation implicitly rules this out since we think this provides the most natural baseline for comparison with the standard representative agent model.

\subsection{Equilibrium and Computation}

Our solution concept is recursive competitive equilibrium. The aggregate state of the economy at $t$ will be the the technology shock, plus $\mu_{m t}$ and $\mu_{n t}$, which denote the distributions of market and home capital across agents indexed by age at $t$. We denote the aggregate state by $S_{t}$. For a given agent, the individual state is given by their age and their two capital stocks. We denote an individual state vector by $s_{t}$. In a recursive competitive equilibrium, prices at $t$ are time invariant 
functions of the aggregate state variable; i.e., $w_{t}=W\left(S_{t}\right)$, and $r_{t}=$ $R\left(S_{t}\right)$. Since our notion of equilibrium is standard, in the interests of space, we do not provide a formal definition. ${ }^{15}$

In equilibrium, individual decision rules depend on the entire state vector, including the two distributions $\mu_{m t}$ and $\mu_{n t}$. Solving for these decision rules would be prohibitively costly in terms of computational time unless they are restricted to being linear; see Rios-Rull (1996). We therefore adopt the following procedure to solve for equilibrium numerically. We linearize the households' first-order conditions, the firms' first-order conditions, and the equilibrium conditions around the model's steady state, and then we use a Schur algorithm to solve for the linearized decision rules; see Klein (2000) for details.

\subsection{Calibration}

We use the model to interpret the choices of households between ages 20 and 74. Thus, we set a period length to be one year and set $T=55$ and $T_{R}=45$, implying that agents retire at 65 . We now tum to the choice of parameter values for our benchmark specification. We emphasize that these choices are only for a benchmark, and that we have carried out sensitivity analyses to explore the implications of alternative values for several parameters. Given that we have a home production model, there is an important decision regarding the division of activity between the home and market. Typically, housing services are treated as a component of market consumption. This does not fit well with a model that describes market output as the result of combining market hours with market capital. We treat housing as a form of home capital, and so in our treatment of the data, we subtract the flow of housing services from market activity. Because the data on market hours fluctuations by age is for the period 1962-2000, we restrict attention to this period for all of our measurement. ${ }^{16}$

As is standard, we follow the procedure of requiring that parameter values are such that the model's deterministic steady state matches the time series averages for several aggregate variables. There are various specific procedures that one may adopt to carry this out. We have experimented with several and found that it made little difference to our conclusions. For our benchmark case, we do the following. The capital share parameter for the market production function is set to $\theta=.3$ to match the capital share of market income in the data. The capital share parameter for the home production function $\eta$ is set to gener- 
ate the same ratio of home investment to market output as in the data. The ratio of home investment to gross domestic product (GDP) in the data is .1248 , and the resulting value is $\eta=.21$. The two depreciation rates are picked on the basis of estimated depreciation by the Bureau of Economic Analysis (BEA). This implies $\delta_{m}=.0654$ and $\delta_{n}=.0568$.

We use a standard procedure to pick values for the stochastic process for the market technology shock. In particular, we construct a series for the Solow residual over the period 1954-2000 using annual data and then estimate an $A R(1)$ process assuming a polynomial time trend. ${ }^{17}$ This leads us to $\rho_{m}=.8953$ and $\sigma_{m}=.0153$. The trend growth rate $g$ is set to a value of .0184 . For the government sector, we choose $G$ so that government spending on goods and services is always equal to .20 of market output, which is roughly the average ratio of government spending to output over the period 1962-2000. We set $\tau_{h}=.25$ and $\tau_{k}=.5$.

This leaves household parameters. There are three sets of such parameters: preference parameters that are constant over the life cycle $(\beta, \xi$, and $\gamma)$, the efficiency units profile $e^{a}$, and the profiles for the preference shifters $\psi^{a}$ and $\omega^{a}$. We choose the discount factor so that households, on average, have investment in market capital that amounts to the share .1203 of market output. The implied value for $\beta$ is $.9563{ }^{18}$ For $\xi$, which determines substitutability between home and market goods and given the empirical results in Rupert et al. (1995) and McGrattan et al. (1997), a reasonable range is between .4 and .5; we set $\xi=.45 .{ }^{19}$ For $\gamma$, which determines the degree of intertemporal substitution in hours of work, there are a variety of estimates to consider, for both men and women, with estimates for the latter usually being greater. In our sensitivity analysis, we explore many values for $\gamma$, but as a benchmark, we set $\gamma=2.5$, which we think is a reasonable compromise between the range of estimates for men and women. This is the estimate obtained by Rupert et al. (2000) using life-cycle data for males in a model that explicitly allowed for time spent in home work as well as market work. As they point out, this estimate is larger than those often found for males, but this is explained by the fact that neglecting home work leads to a negative bias in previous estimation procedures.

We choose the efficiency units profile for market work for the household by matching data on male wages over the life cycle. In particular, we use cross-section data from the March CPS for the years 1975-1981 and then use the fitted values from a regression on a constant, age and 


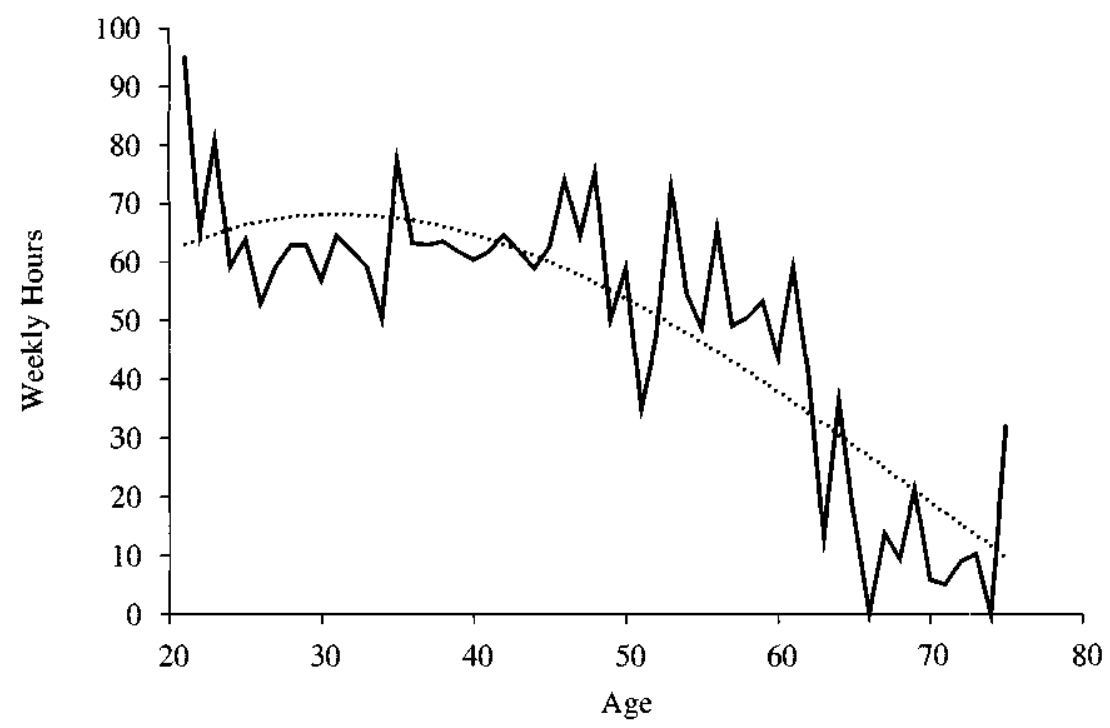

Actual

Fitted

Figure 1

Household profile for market hours

age squared ${ }^{20}$ The parameters $\psi^{a}$ and $\omega^{a}$, which dictate the relative weights on market versus home consumption and on consumption relative to work, are important because they influence the absolute amount of time spent working and the relative amount of time spent on market and home work. Thus, we choose these parameters to match the profile of time spent on home and market work, given the other parameters. We obtain life-cycle profiles of time spent on market and home work for married couple households from the Time Use Study. In particular, we use data from the Michigan Time Use Longitudinal Panel Study for the years 1975-1981. We use data on market and home hours for married households and use the fitted values from a regression on a constant, age, age squared, and age cubed. Figure 1 shows the life-cycle profile for market hours that we use in the calibration, and Figure 2 shows the life-cycle profile for home hours. Figure 3 shows the calibrated profile for $\psi$ over the life cycle, and Figure 4 shows the profile of $\omega$ over the life cycle. ${ }^{21}$

As can be seen, the calibrated profile for $\psi$ has a U-shape, increasing during the middle part of the life cycle, whereas the profile for $\omega$ is increasing over time. This profile has a large jump at retirement age 


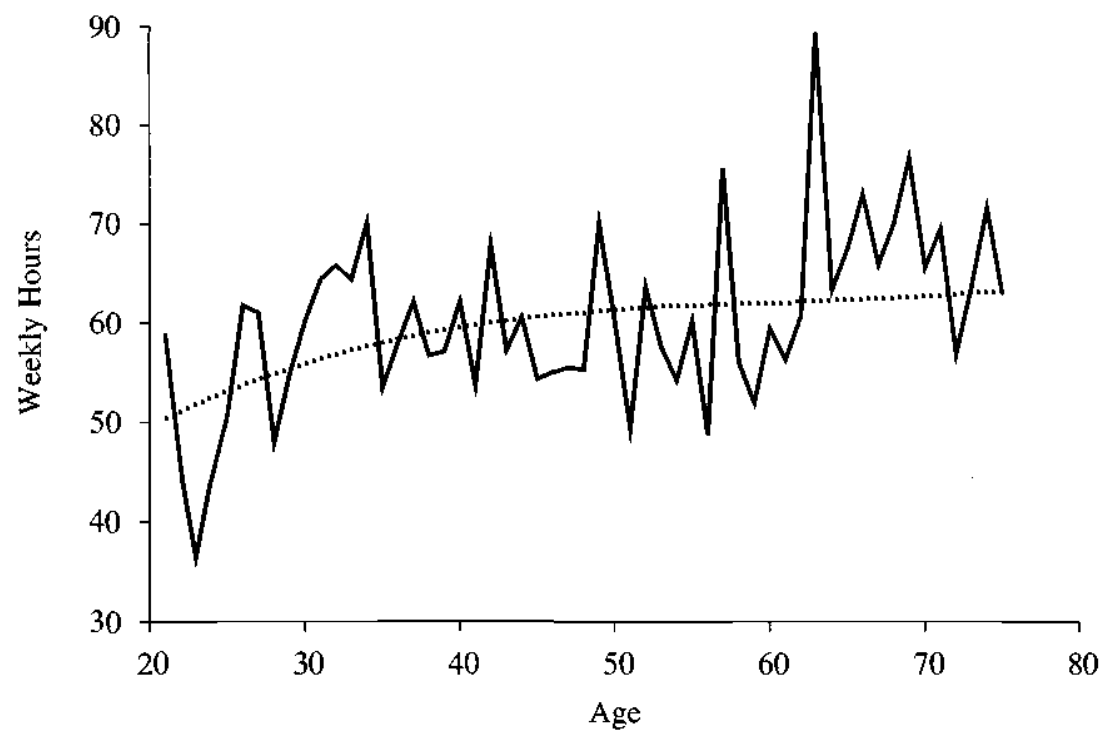

Actual

Fitted

Figure 2

Household profile for home hours

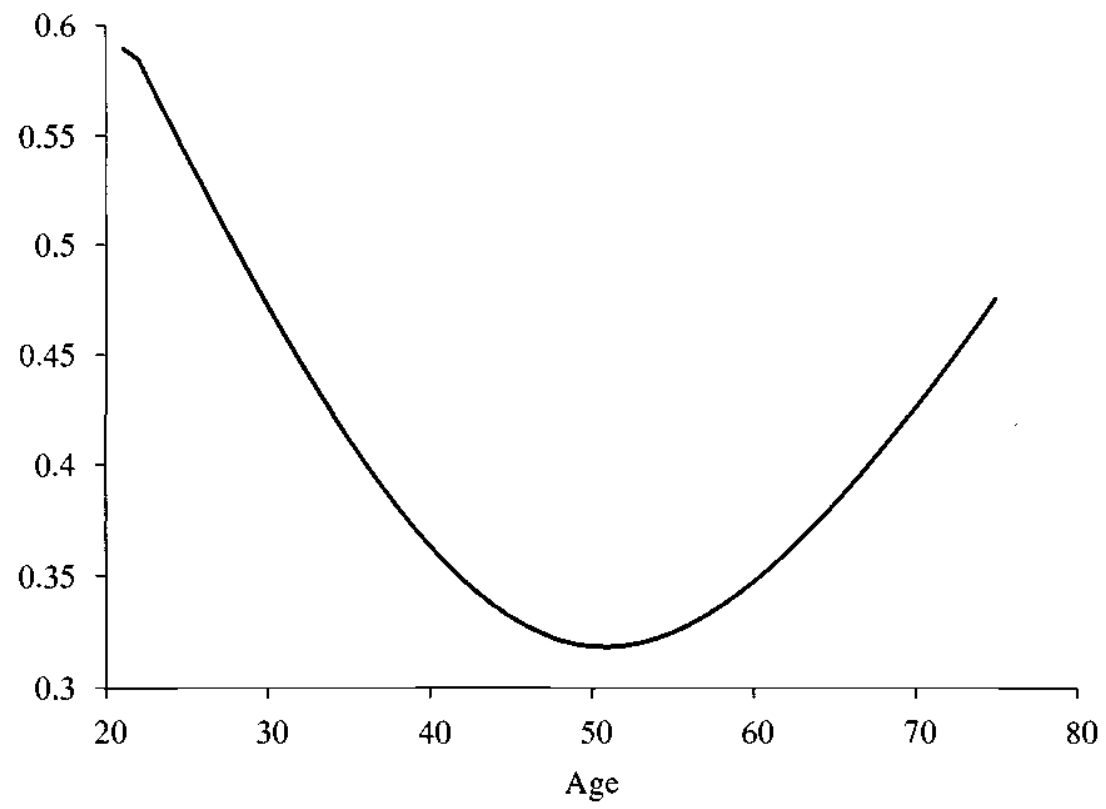

Figure 3

Calibrated profile for $\psi$ 


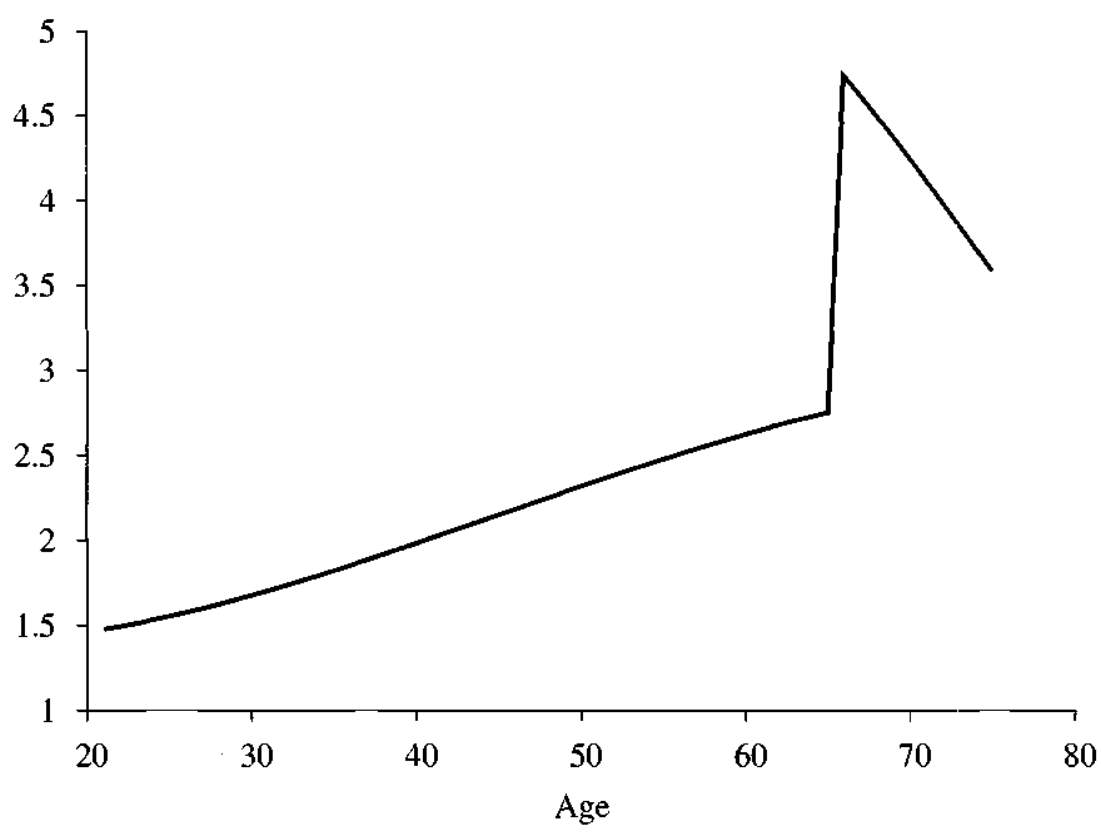

Figure 4

Calibrated profile for $\omega$

since we require the first-order condition for total work to hold on either side of retirement. Perhaps not surprisingly, the calibration then requires that the disutility of working increases rather sharply at retirement. To understand the shape of the $\omega$ profile, note that in the steadystate equilibrium of this model, the standard first-order conditions for market hours at each point of the life cycle with positive market hours implies a relationship between total hours (market plus home) at each period relative to hours in the first period; relative efficiency units at each point relative to the first period; and the value of $\gamma$, the parameter that determines the intertemporal elasticity. Our calibrated hours series implies a series for total hours that is hump-shaped, similar to the efficiency units profile. The profile for $\omega$ is increasing over time because with $\gamma=2.5$, the data on total hours and efficiency units can be reconciled only with an increasing profile for $\omega$. Given the series for total hours, the series for $\psi$ effectively justifies the split of total hours between home and market work over the life cycle.

Last, we need to assign a value to the endowment of home capital that a household receives when they begin economic life. We set this 
Table 12

Parameters for benchmark calibration

\begin{tabular}{llllllllllll}
\hline$\beta$ & $\theta$ & $\eta$ & $\delta_{m}$ & $\delta_{h}$ & $g$ & $\rho$ & $\sigma_{m}$ & $\tau_{h}$ & $\tau_{k}$ & $\gamma$ & $\xi$ \\
\hline .967 & .30 & .21 & .065 & .057 & .018 & .895 & .0153 & .25 & .50 & 2.5 & .45
\end{tabular}

Table 13

Properties of aggregate fluctuations

\begin{tabular}{lcccc}
\hline variable $(x)$ & $\sigma_{x}$ & $\sigma_{x} / \sigma_{Y_{m}}$ & $\operatorname{corr}\left(x_{t}, x_{t-1}\right)$ & $\operatorname{corr}\left(x_{i}, Y_{m t}\right)$ \\
\hline A. U.S. data, 1962-2000 & & & \\
$Y_{m}$ & 2.23 & 1.00 & .54 & 1.00 \\
$Y_{m p}$ & 2.36 & 1.06 & .52 & .99 \\
$C_{m}$ & 1.37 & .61 & .65 & .91 \\
$I$ & 5.68 & 2.55 & .56 & .89 \\
$H_{m E}$ & 1.95 & .87 & .58 & .86 \\
$H_{m H}$ & 1.79 & .80 & .55 & .75 \\
$Y_{m p} / H_{m E}$ & 1.14 & .51 & .34 & .47 \\
B. Model & & & & \\
$Y_{m}$ & 2.25 & 1.00 & .52 & .00 \\
$C_{m}$ & 1.12 & .50 & .56 & .97 \\
$I$ & 4.99 & 2.22 & .51 & .99 \\
$H_{m}$ & 1.05 & .47 & .54 & .98 \\
$Y_{m} / H_{m}$ & 1.23 & .55 & .51 & .99 \\
\hline
\end{tabular}

to .2 in our benchmark since with this value, we did not need any large departures from the profiles for the $\omega^{a}$ and $\psi^{a}$ to match the life-cycle hours profiles. This condition is obviously somewhat weak; however, we found that this parameter does not matter for the model's businesscycle properties. This completes the calibration. Table 12 summarizes the key parameter values for our benchmark economy.

\section{Results}

In this section, we present the results for our benchmark model. As is standard, we simulate the model for 39 years, starting from the deterministic steady state, and compute sample statistics from the equilibrium time series. We then repeat this 1000 times and average across the trials. Panel A of Table 13 shows the standard set of aggregate business-cycle statistics for the U.S. economy, and Panel B shows the same set of statistics for our benchmark model. 
A few remarks on the data are in order. The measure of output that we use in Panel A is GDP per capita, less the imputed value of owneroccupied housing services. As discussed earlier, subtracting the value of owner-occupied housing services is consistent with viewing this as a nonmarket service that derives from the stock of home capital. We also report a measure of private GDP. Although our model has a government sector, by assumption in our model, the government sector fluctuates as much as the private sector and is perfectly correlated with fluctuations in the private sector. In reality, although the government sector does fluctuate about as much as the private sector, the two series are virtually uncorrelated. Our measure of consumption is spending on consumer nondurables and services (net of the imputed service flow for owner-occupied housing). Spending on consumer durables is counted as investment in home capital and hence is included in the investment category. Because our model abstracts from inventories, our investment series excludes this component. We report two hours series-one from the household series and one from the establishment series. The productivity series reported is for productivity in the private sector and is derived from using the data on private GDP and the hours series from the establishment series.

The relationship between the model statistics and their real-world counterparts is fairly typical for this literature, so we do not devote much space to it here. Note, however, that if one calibrates to annual data, then Solow residuals are large enough to account for virtually all fluctuations in market output, whereas in a quarterly model, the typical result is that the model accounts for roughly two-thirds of output fluctuations. ${ }^{22}$

Our focus here is on the ability of the model to account for fluctuations in hours, and as we can see from the above tables, the model can account for only about $60 \%$ of relative fluctuations in market hours. Also, consistent with the findings of Rios-Rull (1996), note that the volatility of aggregate hours in the overlapping generations model is very similar to that of the infinitely lived representative agent model. The relative standard deviation of hours here is .47 , whereas it is .52 in the infinitely lived representative agent model, with the same values for labor supply elasticities. However, note that in the infinitely lived representative agent model, all labor services were equally productive, so that the variability of labor services in efficiency units was the same as the variability of labor services as measured by units of time. This is not the case in the calibrated overlapping generations model. If we 
Table 14

Relative standard deviation of market hours by age group

\begin{tabular}{lrll}
\hline Age group & Data & Model & Model/data \\
\hline $16-19$ & 2.23 & - & - \\
$20-24$ & 1.23 & .39 & .32 \\
$25-34$ & .86 & .35 & .41 \\
$35-44$ & .64 & .35 & .54 \\
$45-54$ & .57 & .46 & .81 \\
$55-64$ & .59 & .97 & 1.64 \\
$65+$ & 1.26 & - & - \\
Aggregate & .80 & .47 & .59 \\
\hline
\end{tabular}

compute the standard deviation of efficiency units of labor input instead, we obtain a value of .50 for the relative volatility. We conclude that the ability of the two models to account for aggregate labor market fluctuations is basically the same.

Since these aggregate statistics have been studied extensively in this context, we do not wish to devote any additional space to them here. Rather, we wish to look more carefully at the model's implications for market hours fluctuations by different age groups. Table 14 presents some summary statistics. The first column shows the standard deviations of hours fluctuations by age group, using the detrending procedure described earlier. As can be seen, these fluctuations exhibit a $\mathrm{U}$-shaped pattern over the life cycle, with prime-age individuals exhibiting the smallest fluctuations.

A striking pattern emerges. In particular, the model's ability to account for fluctuations in hours increases as we consider older age groups. Although the magnitude of fluctuations exhibits a $U$-shaped profile over the life cycle in both the data and the model, this shape is much more pronounced in the data. In the model, the profile is effectively flat over the first part of the life cycle and increasing thereafter. We also note that in the model, the high variability of the age group $55-64$ is due to the individuals in the 60-64 age group. If one considers the age group 55-59, the model predicts a relative standard deviation of roughly .73 , which is much closer to the actual data. A simple message emerges from Table 14. Although the various income and substitution effects present in this model are sufficient to account for only about $60 \%$ of all fluctuations in hours, the extent of the shortcoming varies dramatically across age groups. We conclude that whatever the key additional mechanisms might be to help account for hours 
fluctuations, these mechanisms must be very nonuniform across age groups, as evidenced by the last column in Table 14.

A key property of these results that we want to emphasize is the pattern of volatility over the life cycle. We will explore the economic factors behind this shape more fully in the next section. But before doing so, we want to emphasize that this pattern is very robust with regard to our calibration strategy. In particular, this pattern is basically independent of the elasticity parameters. Changing the elasticity parameters basically generates parallel shifts in the curve that shows volatility over the life cycle.

\section{Understanding the Life-Cycle Pattern of Volatility}

In this section, we try to shed some light on why the life-cycle profile of fluctuations takes on the shape that it does. Note that in the model, all shocks are aggregate in the sense that all individuals face exactly the same shock processes. The differing responses of individuals over the business cycle are purely the result of individuals responding differently to common shocks. There are two different aspects to heterogeneity in the model. The first is that individuals are of different ages and hence at any point in time the agents that are alive have different planning horizons. In our model, this is also associated with different weights on home and market consumption, different weights on consumption and time spent working, and different productivities in market work. All of these differences represent heterogeneity in the exogenous component of an individual's state vector. The second source of heterogeneity is in the endogenous component of an individual's state vector. Optimal decisionmaking implies that, on average, individuals of different ages will have accumulated different amounts of capital. Individuals with different amounts of capital will potentially respond differently to the same shock. In seeking to understand the pattern of hours volatility over the life cycle predicted by the model, it will be useful to acknowledge these two different sources of heterogeneity.

To learn about the role that various features play in shaping the resulting profile of hours volatility over the life cycle, we find it instructive to compare outcomes across models in which specific model features are varied. If we do this type of analysis in the context of the full general-equilibrium model that we studied earlier, a difficulty emerges since with any change in model features we will potentially generate different parameters from a given calibration procedure. The 
equilibrium properties of the stochastic wage and rental rate processes may also vary. This makes it more difficult to assess the role of the various changes. This would also be true even if we did not redo the calibration with the new model feature present.

Because of this, in this section, we have chosen to focus on a comparison of decision theoretic cases in which we take a given stochastic process for wage (or rental) rates, solve individual decision problems with different features, and then compare the outcomes. We feel that this is a useful way to isolate the manner in which changes in features of the individual decision problem lead to changes in the volatility of hours for a given exogenous stochastic process for wages (or rental rates).

\subsection{Case I: The Pure Effect of the Time Horizon}

We begin by focusing on the pure effects of differences in the time horizon; i.e., we are interested in how the time horizon affects the response of an individual to a given shock, holding all other factors constant, such as the stock of capital owned by the individual, or the individual's productivity in market work. We will do this in two contexts, one in which there is no retirement, and the other in which there is retirement since it is of separate interest to understand the role of retirement. In this section, we present results for the case of no retirement. For simplicity, we abstract from home production in these exercises. Hence, we consider an individual with a period utility function given by:

$\log \left(c_{t}\right)-\frac{\omega}{\gamma} h_{t}^{\gamma}$

We consider an individual with constant efficiency in market work and who begins life with zero assets. The individual works for $T$ periods and then dies. We assume that the individual faces stochastic processes for wage and rental rates that approximate those in the benchmark equilibrium above, except that we assume that the mean rental rate of capital is such that the return to capital exactly offsets the effect of discounting. In each exercise, we allow for only one stochastic process, holding the other price constant. We do this analysis for various values of $T$. In each case, we simulate the decision problem and compute the variability of hours at each stage of the life cycle. One appealing feature of this specification is that the individual has no life-cycle motive for capital accumulation, so that in the absence of shocks the individual 
would not accumulate any capital-he or she would simply work the same amount each period and then consume their income.

All results reported below are for the case of $\gamma=2.5$. We assume that wage and rental rate stochastic processes follow $A R(1)$ processes with a persistence parameter of .75. Average hours of work in the no-shock case are equal to .33 , and average wages are equal to .96 . The standard deviations in the tables below are based on the raw series and are not HP-filtered since we are not comparing these to actual data.

Comparing the volatility of, say, those in years $1-5$ of life across cases with different $T$ provides a way to assess the role of the time horizon in shaping the magnitude of the response. Intuitively, in this model, the key mechanism through which changes in wages and capital rental rates influence hours of market work is through intertemporal substitution. The shorter the horizon, the less scope there is for intertemporal substitution. In fact, in the extreme case of a one-period context, the intertemporal substitution effect vanishes. Table 15 shows the results of this exercise. As in the previous analysis, we interpret our individuals as starting life at age 20 .

Reading down the columns of the table, one sees the various lifecycle profiles of volatility. Two patterns emerge. First, for a given life cycle, volatility decreases as the household ages. Second, holding age of the household fixed, volatility increases as we increase the number of periods remaining. The two patterns are strongly related. In fact, the table reveals that the volatility in hours is effectively determined by how many periods remain in the household's planning horizon:

Table 15

Effect of planning horizon: wage shocks, no retirement

\begin{tabular}{lllllll}
\hline Age interval & $T=5$ & $T=15$ & $T=25$ & $T=35$ & $T=45$ & $T=55$ \\
\hline $20-24$ & .026 & .115 & .179 & .223 & .252 & .272 \\
$25-29$ & & .087 & .161 & .214 & .249 & .272 \\
$30-34$ & & .044 & .129 & .193 & .235 & .264 \\
$35-39$ & & & .087 & .163 & .215 & .249 \\
$40-44$ & & & .042 & .128 & .190 & .232 \\
$45-49$ & & & & .087 & .162 & .213 \\
$50-54$ & & & & .042 & .128 & .190 \\
$55-59$ & & & & & .087 & .162 \\
$60-64$ & & & & & .042 & .128 \\
$65-70$ & & & & & .087 \\
$71-75$ & & & & & & .042 \\
\hline
\end{tabular}


holding the number of periods remaining fixed, it is basically irrelevant how old the household is. The decreasing pattern is consistent with the intuition that we expressed earlier-as the horizon becomes shorter, there is less opportunity for intertemporal substitution. Or put somewhat differently, as the horizon becomes shorter, the shocks appear to be more permanent, and with balanced growth preferences, individuals do not change hours of market work in response to a permanent shock to wages (if they have no additional income). Recall that, given our earlier comment, capital holdings do not vary systematically with age in the deterministic version of this problem.

The table also allows us to assess the quantitative significance of the time horizon effect. The table indicates that once the number of years remaining is around 30 , the effect of further increasing the number of periods remaining is relatively small. However, comparing the volatility at different points in the life cycle, we see that the associated effects are very large. Specifically, consider the final column of the table, which corresponds to a planning horizon of 55 years. Volatility in the first five years of working life is more than six times as large as volatility in the final five years of working life, and about one-third larger than volatility during the middle five years of working life.

We have done this same exercise using the stochastic process for rental rates on capital rather than the stochastic process on wage rates. The patterns are virtually identical, though the volatility is about half as much on average. Since there is little additional information, we do not present the results for this case.

\subsection{The Effect of Retirement}

Next, we consider the same situation except that we add retirement. In particular, we consider an individual who works for 45 periods and then retires for $T_{R}$ periods, where we vary $T_{R}$. The results are shown in Table 16. As before, each column depicts the life-cycle pattern of volatility for a given length of retirement. The first column in Table 16 is identical to the second to last column in Table 15-both correspond to a case in which the worker works for 45 years and then dies. A striking new pattern appears. With the prospect of retirement, volatility no longer decreases monotonically over the life cycle. In fact, once $T_{R}$ exceeds zero, we see that the highest volatility always occurs in the final five years of working life, which is just the opposite of what we found in the case without retirement. Looking at the results more 
Table 16

Effect of retirement: wage shocks

\begin{tabular}{lllll}
\hline Age & $T_{R}=0$ & $T_{R}=10$ & $T_{R}=15$ & $T_{R}=20$ \\
\hline $20-24$ & .252 & .253 & .253 & .255 \\
$25-29$ & .249 & .254 & .256 & .260 \\
$30-34$ & .235 & .247 & .252 & .256 \\
$35-39$ & .215 & .235 & .242 & .249 \\
$40-44$ & .190 & .225 & .236 & .246 \\
$45-49$ & .162 & .219 & .235 & .249 \\
$50-54$ & .128 & .222 & .247 & .266 \\
$55-59$ & .087 & .256 & .291 & .316 \\
$60-64$ & .042 & .390 & .427 & .451 \\
\hline
\end{tabular}

carefully, we see volatility is not monotone as we read down the columns. Loosely speaking, the pattern is for volatility to be roughly constant over the first 15 or so years of working life, then to decrease somewhat prior to increasing over the final ten or fifteen years of working life. The overall pattern is roughly U-shaped.

Why does the final five years of working life now have the highest level of volatility? The reason is once again intuitive. The presence of retirement extends the worker's planning horizon beyond the final period in which he or she works. If a worker in the final year of working life realizes a positive wage shock in the no-retirement case, he or she will increase current-period consumption by the same amount by which labor income increases. And with balanced growth path preferences, this results in no increase in hours of work. In contrast, a worker with a large number of periods left will not increase current consumption by the full amount by which current labor income increases since he or she will save some of it to supplement consumption when wages are low sometime in the future. When we add a retirement period, a worker in the final period of working life will spread any increased income across all retirement periods, so that current consumption increases by only a fraction of the increase in current labor income. If the same individual were to have additional working periods after the current period, he or she would shift less income forward since in the face of a persistent positive shock to wages, he or she would plan on working more, not just this period but also in future periods. This lessens the incentive to work more this period and explains why the response is even larger for someone facing retirement. Put somewhat 
differently, if a worker is in the final period of working life prior to retirement and experiences a positive persistent shock to wages, the fact that he or she will retire next period makes the shock seem more transitory than it really is, and intertemporal substitution is larger in response to less persistent shocks. Of course, this effect is present not only in the final period prior to retirement but also in earlier periods, which is why we see that volatility will increase not only in the final five years of working life but also earlier.

Intuitively, the model without retirement predicts a monotone decreasing pattern for volatility over the life cycle, whereas the argument just made suggests that retirement gives rise to an increasing pattern for volatility over the life cycle. The size of these effects are not uniform over the life cycle, so when they are combined, we see that one dominates over the early part of the life cycle and the other dominates over the latter part, giving rise to the rough U-shaped pattern.

It is also important to note the quantitative importance of retirement. As just remarked, the pattern of volatility over the life cycle is roughly $\mathrm{U}$-shaped. However, going from the first five periods to the middle five periods, the decrease in volatility is only about $10 \%$, whereas in going from the middle five years to the final five years, the volatility of hours almost doubles. This quantitative pattern is reminiscent of what we found in our benchmark simulations. While the model does generate a U-shaped pattern, the lefthand side of the $U$ is in fact almost flat.

The key message from this exercise is that adding retirement is likely to have a large effect both qualitatively and quantitatively on the nature of volatility over the life cycle. However, it should also be noted that once the retirement period reaches ten years, the resulting profile of volatility over the life cycle is in fact relatively constant in the face of additional increases in the retirement period.

Though we do not deal with the case of endogenous retirement, it is worth noting that in such a context, one would probably expect the sharp increase in volatility just prior to retirement to be mitigated somewhat. An individual who realizes a positive wage shock at age 65 would potentially postpone retirement to take further advantage of the increased earnings opportunities rather than focusing all of the increased hours in one period. Conversely, the fact that individuals become eligible for social security benefits at age 62 could cause individuals to have much larger responses to negative shocks if a persistent negative shock leads them to opt for early retirement. 
Table 17

Effect of life-cycle earnings: wage shocks, no retirement

\begin{tabular}{llll}
\hline & \multicolumn{3}{l}{ Standard deviation of hours } \\
\cline { 2 - 4 } Age & No peak & Peak $=2$ & Peak $=3$ \\
\hline $20-24$ & .272 & .293 & .303 \\
$25-29$ & .272 & .252 & .245 \\
$30-34$ & .264 & .212 & .191 \\
$35-39$ & .249 & .175 & .143 \\
$40-44$ & .232 & .149 & .112 \\
$45-49$ & .213 & .146 & .118 \\
$50-54$ & .190 & .169 & .162 \\
$55-59$ & .162 & .186 & .203 \\
$60-64$ & .128 & .196 & .243 \\
$65-69$ & .087 & .211 & .285 \\
$70-74$ & .042 & .220 & .323 \\
\hline
\end{tabular}

\subsection{The Effect of Life-Cycle Changes in Wages}

We now ask how the presence of changes in wages over the life cycle influences the pattern of volatility over the life cycle. To better isolate the role of this factor, we consider a somewhat stylized version in which wages over the life cycle are represented by a symmetric triangle. In the benchmark case considered above, efficiency units were always equal to one. We now consider cases where the peak efficiency units are 2 and 3 . Table 17 presents the results. For this exercise, we assume that the worker works for 55 periods and then dies.

As noted earlier, the life-cycle profile of volatility in the first column is decreasing. As we move from the first column to the second column, we see that the amount of volatility is decreased in the middle of the life cycle and is increased at the two edges of the life cycle. Note that the decrease is largest for the periods in which efficiency units are greatest. Why does this happen? We believe there is a simple intuitive explanation for this. There are two perspectives from which one can view the mechanics of intertemporal substitution in this model. One perspective is that when an individual engages in intertemporal substitution, he or she is effectively substituting production of income today for production of income at some future date; i.e., he or she is choosing to produce income when it is most efficient to do so. The other perspective is that the individual is trading off leisure today for leisure in 
the future. We argue that both of these perspectives lead us to expect volatility of hours of work to be lower during periods of high efficiency units.

We begin with the first perspective. If one is considering trading off production of income in two periods in which efficiency units differ, then the trade-off in hours will not necessarily be one-for-one. In particular, the change in hours from the lower-productivity period must be greater to compensate for the change in hours from the higherproductivity period. This suggests that intertemporal substitution in this context will necessarily lead to lower changes in hours in the high-productivity period and higher changes in hours in the lowproductivity period, as we see in Table 17. Next, consider the second perspective. If leisure is lower in the period with high efficiency units, then at the margin, leisure is more valuable in these periods. It follows that if the individual is trading off leisure in the different periods, then it takes more leisure in the low-efficiency unit periods to compensate for one unit of leisure in the high-efficiency units period. Again, this suggests that hours should be less volatile in the high-efficiency unit periods.

The results in Table 17 also reflect another factor that is mechanical in nature. To see this, note that if we change the profile of hours over the life cycle in the absence of shocks but keep the absolute magnitude of fluctuations in hours worked over the life cycle constant, then it would actually appear that percentage fluctuations in hours worked were lower during periods in which efficiency units are higher. To assess the magnitude of this mechanical effect, we have also computed standard deviations of the business-cycle component of hours worked by age by using actual hours rather than the log of hours. When we did this, we found a $U$-shaped pattern of volatility that was of roughly the same quantitative magnitude as in Table 17, so we conclude that this mechanical channel is not driving the results. The potential size of this effect can also be gauged by noting that the variation in hours worked over the life cycle is not that large.

As with the previous factors, it is important to assess the quantitative magnitude of the effect associated with the life-cycle pattern of efficiency units. The case of peak efficiency units equal to two is of roughly the appropriate order of magnitude in terms of reality. As can be seen, this effect decreases volatility of hours in the middle of the life cycle by about one-third, and increases the volatility of older workers quite substantially. 
In this subsection, we have focused on life-cycle changes in wages. However, we note that if there were life-cycle changes in the value of leisure, we would get similar effects. In particular, if leisure is valned differently at different points, then intertemporal tradeoffs are altered. Given the similarity to the effects just analyzed, we do not present any results for this particular specification. But it should be noted that our benchmark calibration does entail a changing value of leisure over the life cycle.

\subsection{Discussion}

The objective of this section was to investigate the role that various factors play in producing the life-cycle profile of volatility generated by our calibrated model. We have shown that three factors seem to be quantitatively significant. First, the finite time horizon matters. Second, the existence of a retirement period matters. And third, the variation of parameters over the life cycle to mimic life-cycle patterns in wages and hours of work also matter. Based on this analysis, we feel that the basic finding regarding volatility of hours over the life cycle is a robust property of the benchmark model with a reasonable parameterization. This is not to claim that our results are robust to all changes in various model features. For example, as mentioned earlier, it is possible that having an endogenous retirement decision in the context of a realistic social security program may influence the nature of fluctuations for older individuals.

What is the relative importance of the three factors just described? To provide an answer to this question, we redid our general-equilibrium calibration exercise keeping everything the same except that we imposed no change in parameters over the life cycle. In particular, we assumed that the efficiency unit profile is constant, as are the profiles for the preference shifters. We then examined the business-cycle properties of this model. The main finding is the following. Volatility of hours worked increases monotonically over the life cycle. The relative volatility of the youngest group is roughly the same as in the benchmark calibration, while the volatility of the oldest group is about twothirds as volatile as in the benchmark calibration. The main impact of the parameters that vary over the life cycle is to depress volatility during the middle years and increase volatility in later years. It remains true in this exercise that the model's ability to account for the pattern of volatility over the life cycle is increasing in age. We conclude from 
this that our key quantitative finding is largely due to the finite horizon and retirement aspects.

\section{International Evidence}

Earlier in the paper, we presented evidence pertaining to properties of labor market fluctuations in the United States. It is of interest to ask to what extent these patterns are also found in other countries. This may well help us think about what factors are generating these patterns. In particular, given that labor market policies and regulations differ quite widely across economies, if these factors are playing a central role, we would expect to see quite different patterns across countries.

Data limitations prevent us from exactly repeating our earlier analysis using data that is available from international statistical agencies such as the Organization for Economic Cooperation and Development (OECD). One would have to go directly to country-level data sets to extract equivalent information. However, data that is available from the OECD does allow us to compare fluctuations in employment to population ratios by age groups for several countries. The time period for which this data is available does vary from country to country, but Table 18 presents summary statistics for several countries for which there is sufficient data. ${ }^{23}$ In this table, we report standard deviations relative to the age group $45-54$.

In all countries but one, we observe that volatility is highest for individuals in the 15-24 group, and that it decreases until we reach the age group 45-54, though for two countries, the volatility increases slightly going from the 35-44 age group to the 45-54 age group. For most countries, relative volatility increases as we move to the oldest group,

Table 18

International evidence

\begin{tabular}{lllllr}
\hline & $15-24$ & $25-34$ & $35-44$ & $45-54$ & $55-64$ \\
\hline Australia (1963-2001) & 1.78 & 1.19 & 1.14 & 1.00 & 7.71 \\
France (1968-2001) & 3.06 & 2.36 & 1.21 & 1.00 & 4.20 \\
Germany (1970-2001) & 1.68 & 1.29 & 1.03 & 1.00 & 1.02 \\
Ireland (1961-2001) & 2.60 & 1.24 & .96 & 1.00 & .86 \\
Norway (1972-2001) & 2.20 & 1.33 & .97 & 1.00 & .84 \\
Portugal (1974-2001) & 3.94 & 1.65 & 1.16 & 1.00 & 1.60 \\
Spain (1972-2001) & 2.74 & 1.79 & 1.09 & 1.00 & .98 \\
Sweden (1963-2001) & 4.24 & 2.22 & 1.54 & 1.00 & 1.53 \\
\hline
\end{tabular}


though for two countries, the change is minimal and for two others, there is a relatively sizable decrease. A more complete assessment of the cross-country data is beyond the scope of this paper, but based on this first look at the data, we conclude that the life-cycle pattern of volatility that we documented for the United States is a robust stylized fact for a broad cross-section of countries.

\section{Summary and Directions for Future Research}

The motivation for this paper consisted of two simple observations. The first motivating observation is that for what many would view as reasonable parameterizations, the standard infinitely lived representative agent household business-cycle model cannot account for the magnitude of fluctuations in aggregate hours of market work over the cycle. According to our benchmark specification and our metric, this model can account for about $60 \%$ of observed fluctuations. This observation has lead many researchers to modify the model in ways to produce greater fluctuations in hours of work for the representative household. The second motivating observation is that fluctuations in hours of market work over the business cycle vary quite dramatically across subgroups in the population. We documented this heterogeneity along two specific dimensions: age and education.

Taken together, this suggests to us a clear direction for research that has been largely ignored. If some groups experience much larger cyclical fluctuations in hours of work than do other groups, this should presumably provide substantial insight into the factors that account for these fluctuations. Or put somewhat differently, if a model produces average fluctuations that are too small, but there is substantial heterogeneity in the magnitude of fluctuations, a natural question to ask is, Which groups are not fluctuating enough? Is the shortfall of fluctuations uniform across all groups, or is it concentrated in a few select groups? The answer to this question should influence the nature of modifications that researchers choose to explore.

This paper has taken a first step in this line of research. We analyzed business-cycle fluctuations in a model in which households differ in age, and we used it to explore the implications of standard shocks and economic forces for the pattern of fluctuations in hours by age. The finding is quite striking. As in the standard model, average hours of market work do not fluctuate enough. But significantly, the main shortfall in fluctuations is accounted for by the behavior of young indi- 
viduals. Taken at face value, this suggests that whatever modifications one believes are empirically relevant for generating larger fluctuations in average hours, these modifications should be such that they interact with age in a very nonneutral manner.

It is beyond the scope of this paper to explore what these modifications might be. One plausible feature is some sort of search friction. One aspect of labor market behavior that varies with age is that younger workers are more likely to be in the process of searching for a career. Aggregate shocks may interact with this process in a distinctive manner.

Another plausible modification could involve human capital accumulation since the nature of human capital accumulation varies over the life cycle. While our model implies that human capital accumulation varies over the life cycle, it implicitly assumed that human capital accumulation at any age occurred at the same rate independently of how an individual allocates his or her time among market work, home work, and leisure. It seems very reasonable to consider modifications of the human capital accumulation process. In this vein, the work of Imai and Keane (2004) is relevant since they argue that allowing for endogenous human capital accumulation greatly increases the estimated labor supply elasticities.

Finally, one qualification that was mentioned earlier also bears repeating. In a model that allows for heterogeneous agents, one must also allow for the possibility that differences in volatilities might also reflect the fact that these agents face different shocks. Even if the shocks are perfectly correlated, the magnitudes of the shocks could vary.

Although our analysis focused solely on the age dimension, the empirical work that we summarized also suggests that a fuller treatment will consider age and human capital accumulation jointly in the business-cycle context. It will be important to assess the key economic forces that alter the way in which individuals who differ in age and human capital respond to common shocks. ${ }^{24}$ More generally, the analysis carried out suggests a research agenda in which macroeconomists take seriously the patterns of hours fluctuations at disaggregated levels to better assess the economy's impulse and propagation mechanisms.

\section{Appendix}

In this appendix, we outline in detail the procedure that we used to produce the statistics reported in Table 3 . As stated in the paper, our 
Table 19

Cyclical fluctuations of hours by age group

\begin{tabular}{llllllll}
\hline & $16-19$ & $20-24$ & $25-34$ & $35-44$ & $45-54$ & $55-64$ & $65+$ \\
\hline$\sigma$ & 6.91 & 3.38 & 2.19 & 1.61 & 1.55 & 1.92 & 5.13 \\
\hline
\end{tabular}

data source is the CPS March Supplement for the years 1962-2000. We use the question on total number of hours of market work in the preceding week to compute average hours per person for all individuals age 16 and over as well as for each of the seven age groups listed in the paper. We use these numbers as our estimates of hours of work per person in the aggregate and by age for each year in the sample, giving us an annual data set for each series.

We define the cyclical component of aggregate hours per person by applying the Hodrick-Prescott (HP) filter to the log of aggregate hours and applying a smoothing parameter of 100 . This series has a standard deviation of 1.99 .

Our basic goal is to determine how changes in aggregate hours per person are accounted for by changes in hours per person of each age group. The first step we take is to apply the Hodrick-Prescott filter to each age-specific series. Doing this produces the values in Table 19. These values display the U-shaped pattern that figured prominently in the analysis in the paper. However, these values are not necessarily the best measures of fluctuations by age for our purposes. There are two issues. First, in going from aggregate data to age-specific data, the survey sample sizes are reduced considerably and there is the possibility of additional noise in the data. Given our detrending procedure this noise will likely show up as cyclical fluctuations. Second, there may be some nonbusiness cycle shocks that affect relative hours across age groups that we do not want to interpret as representing business-cycle shocks. Table 20 presents cross-correlations for the various age-specific cyclical components with each other and the aggregate component.

As expected, one sees that each of the age-specific series is highly correlated with the aggregate, with the exception of the over-65 age group. This group also accounts for very few hours worked. In fact, the basic pattern is that the greater the age-specific hours worked, the greater is the correlation with the aggregate. All of the crosscorrelations between age groups are also fairly positive. However, the basic pattern suggests that measurement error and/or some agespecific shocks may be a factor. 
Table 20

Contemporaneous correlations across age groups, HP filtered data

\begin{tabular}{lcrrrrrrr}
\hline & $16-19$ & $20-24$ & $25-34$ & $35-44$ & $\mathbf{4 5 - 5 4}$ & $55-64$ & $65+$ & Agg \\
\hline $16-19$ & 1.00 & & & & & & & \\
$20-24$ & .81 & 1.00 & & & & & & \\
$25-34$ & .81 & .92 & 1.00 & & & & & \\
$35-44$ & .70 & .84 & .92 & 1.00 & & & & \\
$45-54$ & .59 & .77 & .82 & .86 & 1.00 & & & \\
$55-64$ & .44 & .50 & .62 & .71 & .79 & 1.00 & & \\
$65+$ & .34 & .19 & .31 & .41 & .39 & .53 & 1.00 & \\
Agg & .80 & .89 & .96 & .96 & .90 & .74 & .43 & 1.00 \\
\hline
\end{tabular}

Table 21

Standard deviations by age group, HP filtered data

\begin{tabular}{llllllll}
\hline & $16-19$ & $20-24$ & $25-34$ & $35-44$ & $45-54$ & $55-64$ & $65+$ \\
\hline Raw & 6.91 & 3.38 & 2.19 & 1.61 & 1.55 & 1.92 & 5.13 \\
Adjusted & 5.67 & 3.04 & 2.12 & 1.58 & 1.41 & 1.46 & 3.11 \\
\hline
\end{tabular}

Hence, the second step in our two-step procedure is to remove the component due to measurement error and/or idiosyncratic shocks. To do this, we take each age-specific series for HP residuals and find the component that is correlated with changes in aggregate hours. We regress each age-specific series on a constant, and current and lagged aggregate hours, and then use the predicted values as our measure of the cyclical component of each series. We experimented with additional lags but found that it made no difference. In fact, except for the groups aged 55 and above, the effect of adding one lag of aggregate hours was very small. Table 21 shows the effect that this has on the measure of volatility for each group.

The first row repeats the standard deviations of the deviations from the HP trend, and the second row presents the values produced by our second step. As can be seen, the changes are relatively small for prime-age individuals, but they are sizable for the youngest and oldest individuals. We should emphasize that for the points that we make in our analysis, the raw data would actually make our case somewhat stronger, so this process of adjustment is not to make our case stronger. As evidence that our adjustment serves its purpose, we note that if one uses the raw data and computes the weighted average of age-specific standard deviations using age-specific hours as weights, then the 
resulting series has a standard deviation that is more than $10 \%$ larger than the aggregate series, but when we do the same calculation using our adjusted series, we obtain the same standard deviation as for the aggregate series. In this sense, we feel that we have isolated the agespecific components of the aggregate fluctuations.

There is one final adjustment that we make for all data reported in the text. This adjustment is irrelevant for purposes of comparing standard deviations across hours series, but it is relevant for comparing volatility of hours with a series such as GDP. Ideally, we would have computed the annual value for aggregate average hours per person by averaging the monthly values for each year. Because we do not have the monthly values for all years, we are unable to do this. Intuitively we would expect that using only the values for March rather than all months would lead to greater variance in the series. To estimate the extent of this effect, we carried out a similar exercise using establishment hours. In particular, for this series, we asked how the standard deviation of the cyclical component changes when we use only the March data as our annual estimate rather than averaging over all twelve months. We find that the standard deviation is larger by $10 \%$ in the case in which only March is used. To retain comparability with other annual series for which we use all observations, in what follows we will make a $10 \%$ adjustment to the standard deviation of all of our hours series based on using only March data. Note that this has no impact on any comparisons of relative volatility across hours series-it is relevant only when comparing the volatility of an hours series to some other series, such as GDP.

\section{Notes}

The authors thank Mark Gertler, Paul Klein, Éva Nagypál, Ken Rogoff, Robert Shimer, and conference participants for useful comments. Rogerson and Wright thank the National Science Foundation for financial support.

1. For example, if one was thinking that the main shortcoming of the model was the absence of rigidities in real wages, one would have to argue that this feature is more important for young workers than it is for prime-age workers.

2. Researchers have previously suggested that trying to understand fluctuations at a more disaggregate level would be useful; an example is Gertler and Gilchrist (1994), who argue that the differences in behavior of large and small manufacturing firms provide additional information about the nature and propagation of aggregate shocks.

3. Some of the standard references on home production in macroeconomics include Benhabib, Rogerson, and Wright (1991); Greenwood and Hercowitz (1991); Greenwood, 
Rogerson, and Wright (1995); McGrattan, Rogerson, and Wright (1997); Baxter and Jermann (1999); and Gomme, Kydland, and Rupert (2001).

4. Standard references in the labor supply literature include, for example, MaCurdy (1981), Altonji (1986), and Pencaval (1986). See Mulligan (1998) for estimates based on other sources.

5. We could also assume that individuals do derive utility from government consumption but that it is separable with respect to the other arguments, which accords with results in the literature, like Christiano and Eichenbaum (1992) and McGrattan et al. (1997).

6. For some other issues, however, shocks to the home technology are crucial; for example, Benhabib, Rogerson, and Wright (1991) show how such shocks can generate a reasonable contemporaneous correlation between productivity and hours, and Hall (1997) finds that home-sector shocks are actually a significant source of aggregate fluctuations.

7. Altematively, one could assume that installed home and market capital can be costlessly transformed into each other, as in Benhabib et al. (1991). For the issues on which we focus here, this would not make much of a difference.

8. In assessing the magnitude of fluctuations in hours, two normalizations have been used in the literature-one normalizes relative to fluctuations in output, while the other normalizes relative to fluctuations in average labor productivity. For our purposes, this choice does not matter because the benchmark specification accounts for roughly twothirds of fluctuations by either metric. Hence, we will simply report the relative volatility of hours to output.

9. Our choice of metric for assessing the magnitude of fluctuations in hours was made in the context of an analysis that emphasizes technology shocks. For a model driven by monetary shocks, this may not be a good metric. Nonetheless, we believe the basic point-that one should consider implications for disaggregated data-to be relevant for all business-cycle models.

10. Using slightly different methods, this basic observation has previously been noted by Clark and Summers (1981). See also Blanchard and Diamond (1990) and Keane and Prasad (1996).

11. There are some attempts to model within-household time allocation explicitly over the business cycle; see, for example, Cho and Rogerson (1988).

12. The role of these shifters will become clear subsequently, but loosely speaking, $\psi^{a}$ allows a household's relative desire for home versus market consumption to change systematically over the life cycle, and $\omega^{a}$ allows a household's value of consumption relative to leisure to change over the life cycle.

13. We are assuming the life-cycle profile of efficiency units is not affected by decisions taken by the individual, such as investment in human capital; this is similar to much of the labor supply literature, but there are exceptions, including Shaw (1989); Chang, Gomes, and Schorfheide (2002); Imai and Keane (2004) and Olivetti (2001).

14. The issue is that events such as having children and buying a home tend to affect the time allocated to home production. One can view these changes as affecting the efficiency of time spent in home production or as affecting one's preferences for home consumption. This choice is not likely to matter for our results. One thing that might be more interesting is to make the timing of these events endogenous, but this is beyond the scope of the current project. 
15. While we will not get into them at all, we note that there are important issues concerning the existence of recursive competitive equilibria in overlapping generations models with incomplete markets. See Kubler and Polemarchakis (2004) for a discussion and some related results.

16. The one exception is in the case of determining the stochastic process for the Solow residual since we think it is important to use as much data as possible to obtain more precise estimates of this process.

17. Specifically, we use data on private GDP as the output measure, market capital as the capital input, and data from the Establishment Survey on hours in private establishments as the labor input.

18. We could have chosen $\beta$ to target a particular rate of return to capital. Our choice implies an after-tax rate of return of approximately $7 \%$. Targeting a lower value would generate a much larger investment share. Ultimately, there is some tension between the various statistics that we ask the model to match. Matching a lower rate of return and a reasonable investment share would require a higher capital share.

19. Related evidence is contained in work by Aguiar and Hurst (2003), who document substantial substitution between expenditures and time in the production of food consumption in response to variation in the opportunity cost of time.

20. It would be more appropriate to use a weighted average of male and fernale wages over the life cycle. Given the selection issues that are more significant in estimating wages for women and the secular changes in women's wages and hours of work, we chose to use men's wages as a proxy.

21. As a side issue, we note that for a given profile of efficiency units $e^{a}$ and elasticity parameters $\xi$ and $\gamma$, one can always find values of the $\psi^{a}$ and $\omega^{a}$ profile such that observed life-cycle hours are consistent with optimization. This should make one leery of studies that claim to identify the value of $\gamma$ from life-cycle data on wages and hours worked since one cannot make this inference without knowing the values of the preference shifters, and they are clearly unobservable.

22. This point is not new-Plosser (1989) found the same result in his model. Note, however, that although Rios-Rull (1996) was an annual model, he also found that his model could account for roughly two-thirds of observed fluctuations in output. The reason for this apparent discrepancy is that he effectively used the Solow residuals computed using quarterly data. In particular, he computed Solow residuals using quarterly data and then aggregated the quarterly process to get an annual process.

23. The data are annual and the numbers in the table are based on standard deviations of cyclical components as defined by the HP filter. Unlike in the earlier tables, we have made no additional adjustments.

24. An early attempt to understand differences in fluctuations in hours of market work across different skill groups is Kydland (1984).

\section{References}

Aguiar, M., and E. Hurst. (2003). Consumption vs. expenditure. NBER Working Paper No. 10307. 
Alexopoulos, M. (2004). Unemployment and the business cycle. Journal of Monetary Economics 51:277-298.

Altonji, J. (1986). Intertemporal substitution in labor supply: Evidence from micro data. Journal of Political Economy 94:S176-S215.

Andolfatto, D. (1996). Business cycles and labor market search. American Economic Review $86: 112-132$.

Baxter, M., and U. Jermann. (1999). Household production and the excess sensitivity of consumption to current income. American Economic Review 89:902-920.

Benhabib, J., R. Rogerson, and R. Wright. (1991). Homework in macroeconomics: Household production and aggregate fluctuations. Journal of Political Economy 99:11661187.

Blanchard, O., and P. Diamond. (1990). The cyclical behavior of the gross flows of U.S. workers. Brookings Papers on Economic Activity 2:85-143.

Chang, Y., Gomes, J., and F. Schorfheide. (2002). Learning-by-doing as a propagation mechanism. American Economic Review 92:1498-1520.

Cho, J. O., and R. Rogerson. (1988). Family labor supply and aggregate fluctuations. Journal of Monetary Economics 21:233-246.

Christiano, L., and M. Eichenbaum. (1992). Current real business cycle theory and aggregate labor market fluctuations. American Economic Review 82:430-450.

Clark, K., and L. Summers. (1981). Demographic differences in cyclical employment variation. Journal of Human Resources 16:61-79.

Danthine, J. P., and J. Donaldson. (1995). Non-Walrasian economies. In Frontiers in Business Cycle Theory, T. F. Cooley (ed.). Princeton, NJ: Princeton University Press.

Den Haan, W., G. Ramey, and J. Watson. (2000). Job destruction and propagation of shocks. American Economic Review 90:482-498.

Gertler, M., and S. Gilchrist. (1994). Monetary policy, business cycles and the behavior of small manufacturing firms. Quarterly Journal of Economics 109:309-340.

Gomme, P. (1999). Shirking, unemployment and aggregate fluctuations. International Economic Review 40:3-21.

Gomme, P., F. Kydland, and P. Rupert. (2001). Home production meets time to build. Journal of Political Economy 109:1115-1131.

Greenwood, J., and Z. Hercowitz. (1991). The allocation of capital and time over the business cycle. Journal of Political Economy 99:1188-1214.

Greenwood, J., R. Rogerson, and R. Wright. (1995). Household production in real business cycle theory. In Frontiers in Business Cycle Theory, T. F. Cooley (ed.). Princeton, NJ: Princeton University Press.

Hall, R. (1997). Macroeconomic fluctuations and the allocation of time. Journal of Labor Economics 15:S223-S250.

Hansen, G. (1985). Indivisible labor and the business cycle. Journal of Monetary Economics 16:309-327. 
Hansen, G. D., and R. Wright. (1992). The labor market real business cycle theory. Federal Reserve Bank of Minneapolis Quarterly Review 16:2-12.

Imai, S., and M. Keane. (2004). Intertemporal labor supply and human capital accumulation. International Economic Review 45:601-641.

Keane, M., and E. Prasad. (1996). The employment and wage effects of oil price shocks: A sectoral analysis. Review of Economics and Statistics 78:389 -400 .

Klein, P. (2000). Using the generalized schur form to solve a multivariate linear rational expectations model. Journal of Economic Dynamics and Control 24:1405-1423.

Krusell, P., and A. Smith. (1998). Income and wealth heterogeneity in the macroeconomy. Journal of Political Economy 106:867-896.

Kubler, F., and H. Polemarchakis. (2004). Stationary Markov equilibria for overlapping generations. Economic Theory, forthcoming.

Kydland, F. (1984). Labor force heterogeneity and the business cycle. Carnegie-Rochester Series on Public Policy 21:173-208.

Kydland, F., and E. Prescott. (1982). Time to build and aggregate fluctuations. Econometrica 50:1345-1370.

Kydland, F., and E. Prescott. (1988). The workweek of capital and its implications. Journal of Monetary Economics 21:343-360.

MaCurdy, T. (1981). An empirical model of labor supply in a life cycle setting. Journal of Political Economy 89:1059-1085.

McGrattan, E., R. Rogerson, and R. Wright. (1997). An equilibrium model of the business cycle with household production and fiscal policy. International Economic Review 38:267290.

Merz, M. (1995). Search in the labor market and the real business cycle. Jourral of Monetary Economics 36:269-300.

Mulligan, C. (1998). Substitution over time: Another look at the evidence. In NBER Macroeconomics Annual, Ben S. Bernanke and Julio J. Rotemberg (eds.). Cambridge, MA: MIT Press.

Olivetti, C. (2001). Changes in women's hours of work: The effect of changing returns to experience. Boston University. Mimeo.

Pencavel, J. (1986). Labor supply of men. In Handbook of Labor Economics, O. Ashenfelter and R. Layard (eds.). Amsterdam: North Holland.

Plosser, C. (1989). Understanding real business cycles. Journal of Economic Perspectives 3:51-78.

Rios-Rull, V. (1996). Life-cycle economies and aggregate fluctuations. Review of Economic Studies 63:465-489.

Rogerson, R. (1988). Indivisible labor, lotteries and equilibrium. Journal of Monetary Economics 21:1-16.

Rupert, P., R. Rogerson, and R. Wright. (1995). Using panel data to estimate substitution elasticities in household production models. Economic Theory 6:179-193. 
Rupert, P., R. Rogerson, and R. Wright. (2000). Homework in labor economics: Household production and intertemporal substitution. Journal of Monetary Economics 46:557579.

Shaw, K. (1989). Life-cycle labor supply with human capital accumulation. International Economic Review 30:431-456.

Shimer, R. (1998). Why is the US unemployment rate so much lower? In NBER Macroeconomics Annual, Ben S. Bernanke and Julio J. Rotemberg (eds.). Cambridge, MA: MIT Press. 


\title{
Comment
}

\author{
Éva Nagypál \\ Northwestern University
}

\section{Introduction}

It has been well known for at least the past two decades that the neoclassical growth model with aggregate shocks, notwithstanding its surprising success in explaining many aggregate phenomena, performs poorly when it comes to explaining business-cycle fluctuations in the labor market.

The work of Gomme, Rogerson, Rupert, and Wright (GRRW) builds on the premise that the understanding of labor market fluctuations over the business cycle is enhanced by moving beyond standard representative agent models. In particular, they propose to analyze models with heterogeneous agents and to study their implications, not only for the aggregate time series, but also for cyclical variation across heterogeneous groups of agents. There are at least two reasons why this is a promising approach to take. First, the empirical evidence shows that different demographic groups exhibit substantially different labor market fluctuations over the business cycle. Second, the heterogeneous impact of business-cycle shocks is an important testing ground for theories of fluctuations that aim to improve the ability of business-cycle models to explain labor market phenomena. Many such theories have been proposed in the literature, so offering additional ways to test the empirical validity of these alternatives is much needed.

For these reasons, I applaud the premise of the paper-the emphasis on heterogeneity in understanding labor market fluctuations--since it sets the stage for further exploration of some crucial questions in the study of labor markets over the business cycle. It also provides a good overview of the relevant empirical and theoretical results. In particular, the empirical results of the paper show that the findings of Clark and Summers (1981) regarding the demographic differences in cyclical vol- 
atility extend to the recessions of the last two decades, while the theoretical part of the paper shows that extending the model studied by Rios-Rull (1996) to include home production and incomplete markets does not significantly alter its implications for the life-cycle pattern of cyclical volatility.

The aim of my discussion is, first, to highlight the most important empirical phenomenon regarding the life-cycle pattern of businesscycle volatility that a theoretical model should aim to explain; second, to clarify why the theoretical approach taken by GRRW fails to explain this phenomenon; and, finally, to push the premise of the paper further and offer an alternative explanation of this phenomenon. Correspondingly, my discussion is organized to deliver three main points.

First, I argue that the difference in the cyclical volatility of hours between prime-age and old workers is second-order in comparison to the substantial difference in the cyclical volatility of hours between young and prime-age workers. Hence, the very high cyclical vanation in the hours of young workers is by far the most important empirical phenomenon that a model that sets out to explain the life-cycle variation in business-cycle volatility should aim to tackle. This means that the authors' focus on the U-shape of cyclical volatility over the life cycle is somewhat misplaced since what is quantitatively relevant is the high cyclical volatility at a young, and not an old, age. Second, I argue that the model studied by GRRW explains only a small fraction of the high business-cycle volatility of hours of the young compared to that of prime-age workers. I explore which of the mechanisms in the GRRW model work in the right direction to explain the higher business-cycle volatility of the hours of the young and which do not. I argue that several of the mechanisms built into the model have no potential to explain the high relative volatility at a young age, and highlight the one mechanism that does. Finally, I suggest that an additional promising mechanism to explain the high cyclical volatility of young workers is the increase in the amount of specific human capital or experience with age. I propose an alternative model with such a mechanism and show that it helps to explain qualitatively why the hours of young workers respond more to business-cycle shocks.

\section{Empirical Evidence on Labor Market Fluctuations over the Life Cycle}

To empirically motivate their study, the authors present measures of cyclical volatility for different demographic groups. Since heterogeneity 
by age is the driving force in the theoretical model studied by GRRW, I restrict my discussion to the results regarding age. It is worth noting, however, that there is also substantial variation in cyclical volatility of hours by education group, a fact that has frequently been noted empirically but that has not received much attention in theoretical work (for an exception, see my earlier work in Nagypál, 2004).

The authors use the March Current Population Survey to construct average hours worked by demographic group for each year between 1962 and 2000. Then, as a measure of cyclical volatility in hours worked by group, they use the standard deviation of the projection of the group-specific Hodrick-Prescott (HP)-filtered log weekly hours series onto the aggregate HP-filtered log weekly hours series. ${ }^{1}$ The measure thus constructed does not have well-established statistical properties and possibly expects more from the available annual data than they might be able to deliver. This is because, in the annual hours data between 1962 and 2000, there are only four distinguishable downturns, i.e., four episodes during which aggregate hours declined, each episode roughly corresponding to a period of recession. This is due to the fact that, even though there were five recessions between 1962 and 2000, the twin recessions of the early 1980s are not distinguishable using annual data. Hence, as a robustness check, I construct a less demanding measure of cyclical volatility. I use the same dataset, but extend it to 2003 to have information on the most recent downturn, which started in 2001. For each downturn, ${ }^{2}$ I calculate the share of total hours worked by each age group in the peak year preceding it:

$s_{i, r}=\frac{H_{i, r}^{p}}{H_{r}^{p}}$

where $H_{r}^{p}$ is the aggregate number of hours worked in the peak year in recession $r$, and $H_{i, r}^{p}$ is the total number of hours worked in the same year by group $i$. I compare this to the share of each age group in the drop in total hours between the peak and the trough year:

$d_{i, r}=\frac{H_{i, r}^{t}-H_{i, r}^{p}}{H_{r}^{t}-H_{r}^{p}}$

where $H_{r}^{t}$ is the aggregate number of hours worked in the trough year in recession $r$, and $H_{i, r}^{t}$ is the total number of hours worked in the same year by group $i$. In Figure 1, I plot $s_{i, r}$ and $d_{i, r}$ by age group averaged over the five downturns in the data. ${ }^{3}$ If there were no difference in the 


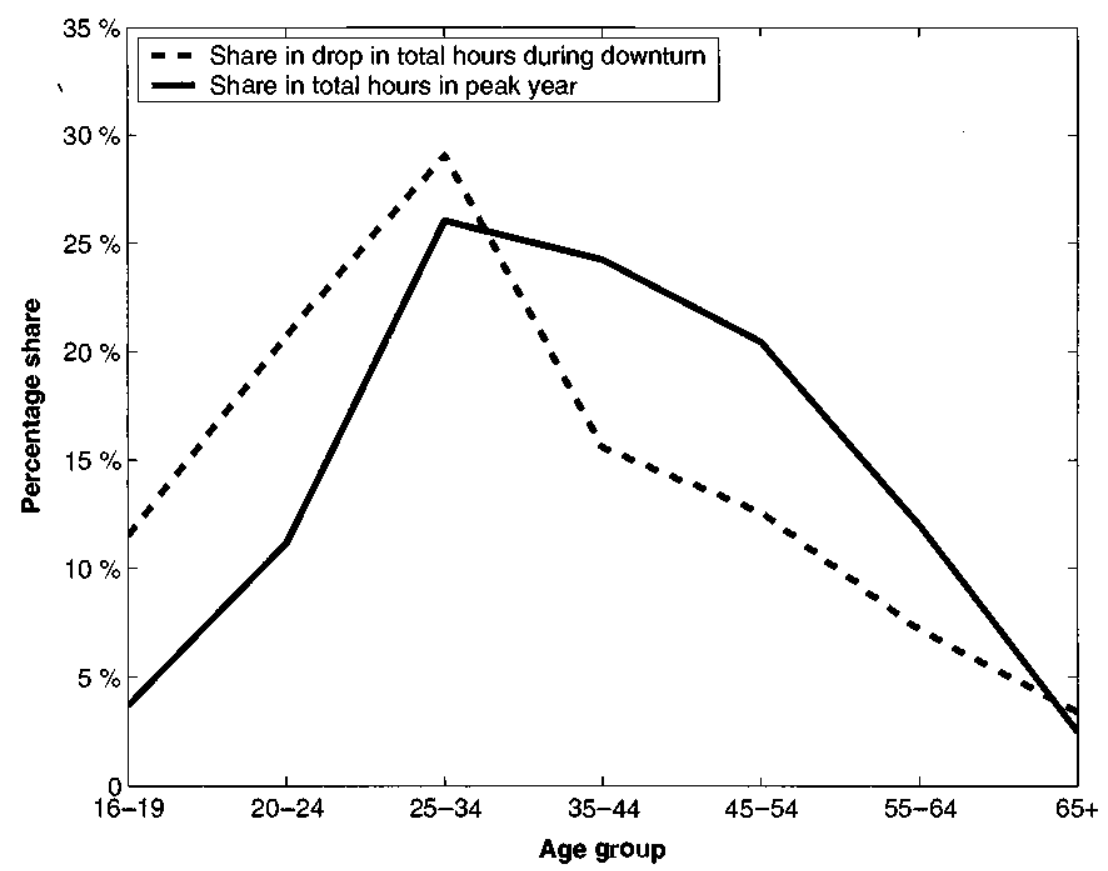

Figure 1

Share of different age groups in total hours in the peak year and in the drop in total hours during the subsequent downturn averaged over the downturns in the data between 1962 and 2003

cyclical volatility of hours across age groups, we would expect hours worked by each age group to shrink by the same extent in a downturn, and we would therefore expect the share in total hours in the peak year, $s_{i, r}$, to be the same as the share in the drop during the downturn, $d_{i, r}$. Instead, what we see is that the share of younger workers in the drop in hours during a downturn is much larger than their share in total hours. This implies that workers in their early thirties and younger bear a disproportionate share of the contraction in total hours. It is this phenomenon that is by far the most important one quantitatively.

How does this measure relate to the one reported by GRRW? Note that $d_{i, r} / s_{i, r}$ is a measure comparable to that used by GRRW, except for a scaling factor. The measure $d_{i, r} / s_{i, r}$, in fact, exhibits a very similar pattern to the measure used by GRRW, both of them having a Ushape. It is clear from Figure 1, however, that the increase at an older age of the relative volatility is exclusively due to workers above the age of 65 , who account for a very small share of total hours in the data 
and who are excluded from the theoretical model of GRRW. Emphasizing the U-shape therefore detracts from the essence of the empirical finding, which is that young workers bear a disproportionate burden in downturns.

With the focus placed so heavily on young workers, it is useful to ask whether it is the extensive or the intensive margin that accounts for the bulk of the drop in their hours during a downturn. To do this, I decompose the drop $d_{i, r}$ into its extensive and intensive margin components, and find that, for all age groups, between $69 \%$ and $80 \%$ of the drop in hours during a downturn is due to the extensive margin, i.e., to the fact that fewer workers are employed, as opposed to workers working fewer hours. This number is somewhat higher than the one reported by GRRW based on a different measure, but it shares the feature that it does not show substantial variation with age.

\section{The GRRW Model}

In the theoretical part of the paper, the authors set out to study the lifecycle version of the neoclassical growth model with technology shocks, variable labor, home production, and incomplete markets to understand the extent to which the above facts can be explained by such a model.

It is instructive to consider the different channels in the model that give rise to differences among the age groups in labor-market responses to aggregate shocks. The first two channels, the time-horizon channel and the time-to-retirement channel, are studied in detail in Sections 6.1 and 6.2 of the paper, so I will review them only briefly.

The time-horizon channel is present because, as agents get older, they have fewer and fewer periods of consumption (of leisure and of consumption goods) remaining. This means that a given innovation in the present discounted value of income due to an aggregate shock induces a larger and larger increase in the consumption of all goods for the remainder periods, including the consumption of leisure in the current period. In other words, the income effect on leisure of an increase in wages is higher as agents get older, which in turn implies a lower response in labor supply to aggregate shocks as agents age. This channel works in the right direction, at least qualitatively, to explain the larger labor-supply response of young workers, as is demonstrated in Section 6.1 . 
Let us next turn to the time-to-retirement channel. ${ }^{4}$ This channel introduces an increasing lifetime profile of labor-supply response to persistent business-cycle shocks. This is due to the fact that, for young workers, an innovation in the aggregate productivity process induces a large income effect on the consumption of leisure due to the persistence of the shock, and to the fact that young workers have many periods over which they can expect to have a higher wage. This large income effect means that the labor-supply response to higher wages is muted for young workers. For workers closer to retirement, the same innovation in the aggregate productivity process induces a smaller income effect on the consumption of leisure because they have fewer periods over which they can expect to have a higher wage. So despite the fact that the shock is persistent, older workers respond to it as if it were temporary. Older workers thus respond to the same shock by increasing their hours more than young workers.

The third channel, and the one the authors emphasize the most, is the life-cycle profile of productivity and preferences channel (or the lifecycle-profile channel). This is present in the GRRW model because the authors assume that the efficiency units of working, the disutility from labor, and the weight placed on the consumption of home goods all change deterministically over the life cycle. One can show that this channel works by influencing the life-cycle profile of three quantities: the ratio of labor income to market consumption, the ratio of home to market consumption, and the ratio of home to market hours. ${ }^{5}$ The ratio of labor income to market consumption matters because it determines the extent of the income effect of a change in the market wage. When labor income is large compared to market consumption (as in Section 6.3, during middle age), the income effect on the consumption of leisure of a temporary wage increase is large, and the labor supply response to this temporary wage increase is therefore small. The ratio of home to market consumption matters because it determines the strength of the income versus substitution effect of a temporary change in the market wage. A temporary change in the market wage has only an income effect on the consumption of the market good, but has an income and a substitution effect on the consumption of the home good. Finally, the ratio of home to market hours matters because it determines the extent to which market hours respond to a wage change for a given change in total and in home hours. The deterministic preference and productivity shifters play a role in determining the labor-supply 
response of the different age groups only to the extent that they influence these three ratios.

These three ratios, though, are observable directly. In particular, it is well known from the empirical consumption literature that household labor income and market consumption profiles are fairly similar, implying that their ratio is roughly constant over the life cycle. The ratio of home to market consumption is more difficult since the authors do not report this measure, but presumably it is closely related to the ratio of home to market hours. The ratio of home to market hours, in turn, can be backed out from the calibration exercise of GRRW since they use both market and home hours to calibrate the deterministic preference and productivity shifters. Since the ratio of home to market hours is strictly increasing with age in the GRRW calibration, one can show that the life-cycle profile channel introduces an increasing volatility of market hours with age in the GRRW calibration. Just as the timeto-retirement channel, the life-cycle-profile channel works in the wrong direction, at least given the values to which GRRW calibrate. ${ }^{6}$

Finally, the last channel is the asset-holding channel. The GRRW model features incomplete markets, and younger workers have lower asset positions than older workers, on average: all workers start their life with no market capital and a fixed amount of home capital, and workers accumulate assets over time for the period of retirement at the end of life. The low asset position of young workers means that, holding all else equal, they work more and consume less for precautionary reasons. Hence, a positive innovation in their income will lead to a higher effect on leisure and thus a lower labor supply response compared to agents with higher asset levels. ${ }^{7}$ This means that increasing asset levels over the working life implies increasing labor supply response to aggregate shocks in the model, so this channel also works in the wrong direction.

To summarize, in terms of explaining the high cyclical volatility of the hours of young workers compared to prime-age workers, the asset-market and the time-to-retirement channels always work in the wrong direction, the life-cycle-profile channel most likely works in the wrong direction given the calibration of GRRW of the home to market share of hours, and the time-horizon channel is the only one that works in the right direction. Given these observations, it is not surprising that the quantitative results of GRRW confirm that the model cannot explain the high cyclical volatility of the hours of young workers. 
Table 1

Cyclical volatility of hours of different age groups relative to age 35-44 in the Rios-Rull and GRRW models, and in the data

\begin{tabular}{llll}
\hline Age group & Rios-Rull $(1996)^{*}$ & GRRW (2004) & Data reported by GRRW \\
\hline $20-24$ & 1.21 & 1.11 & 1.92 \\
$25-34$ & 1 & 1 & 1.34 \\
$35-44$ & 1 & 1 & 1 \\
$45-54$ & 1.72 & 1.31 & 0.89 \\
$55-64$ & 1.72 & 2.77 & 0.92 \\
\hline
\end{tabular}

* In Rios-Rull (1996), age group 25-34 is not distinguished from age group 35-44, and age group $45-54$ is not distinguished from age group 55-64.

In terms of the quantitative results, it is worth noting that three of the above four channels are already present in the model studied by Rios-Rull (1996). Since he studies a complete-markets version of the GRRW model without home production, the asset-market channel is not present in his model, while the life-cycle-profile channel has a more limited role. Since both of these channels work in the wrong direction, it is not surprising that the results of GRRW are, if anything, less successful at explaining the high cyclical volatility of the hours of young workers. Table 1 compares the results of GRRW and those of Rios-Rull by calculating the cyclical volatility of hours for each age group relative to the age group $35-44$. We can see that the two sets of results are rather similar, implying that the additional channels are quantitatively not very important. ${ }^{8}$

\section{Accumulation of Human Capital over the Life Cycle}

To explain the life-cycle pattern of cyclical volatility more successfully, one needs to explore additional channels through which differences in age groups arise. This is an issue I take up in this section by exploring one additional channel, the human-capital channel, and examine whether it works in the right direction, at least qualitatively.

Differences in human capital are often emphasized in labor economics as one of the major differences between young and old workers. There are, of course, different measures of human capital, the two most prominent ones being education and experience. At first glance, it might seem that differences in education could explain some of the differences in the life-cycle profile. Younger workers (at least under a certain age) might have somewhat less education and, as is documented 


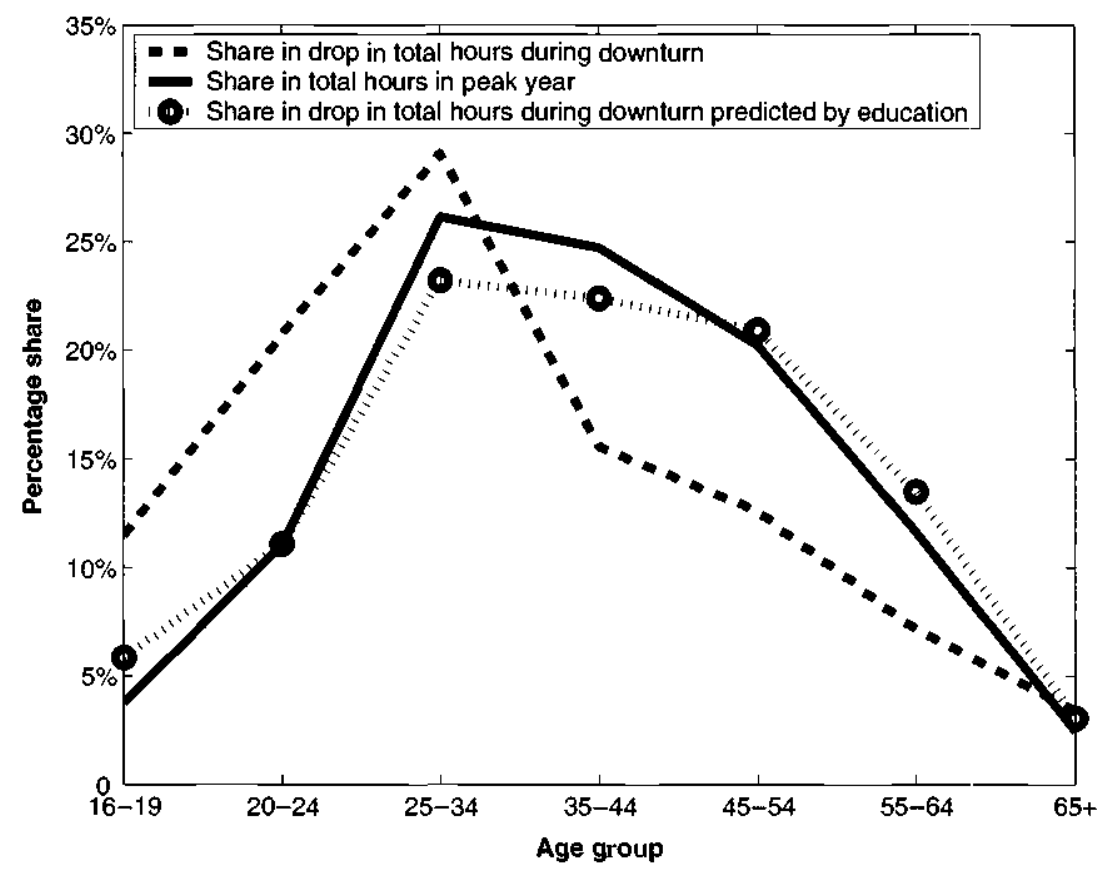

Figure 2

Share of different age groups in the drop in total hours during a downturn predicted by education variation

in the paper, there is significant variation in the response of hours to business-cycle shocks by education. It turns out, though, that if the only variation allowed across the age groups was in education, this would not be enough to explain the differential business-cycle responses. To show this, I plot in Figure 2, for each of the different age groups plotted in Figure 1, the share in total hours in the peak year and the share in the drop in total hours during the downturn, together with the share in the drop in total hours during a downturn that would be predicted solely by a different educational composition of the age groups. We see that it is only for teenagers that conditioning on education works in the right direction. The reason for this is the secular increase in educational attainment over the period of study, which means that workers in their late twenties and thirties tend to have more education, and thus a lower predicted business-cycle response, than workers in their forties and fifties.

Another, more promising variation in human capital across age groups is in specific human capital, or experience. Younger workers 


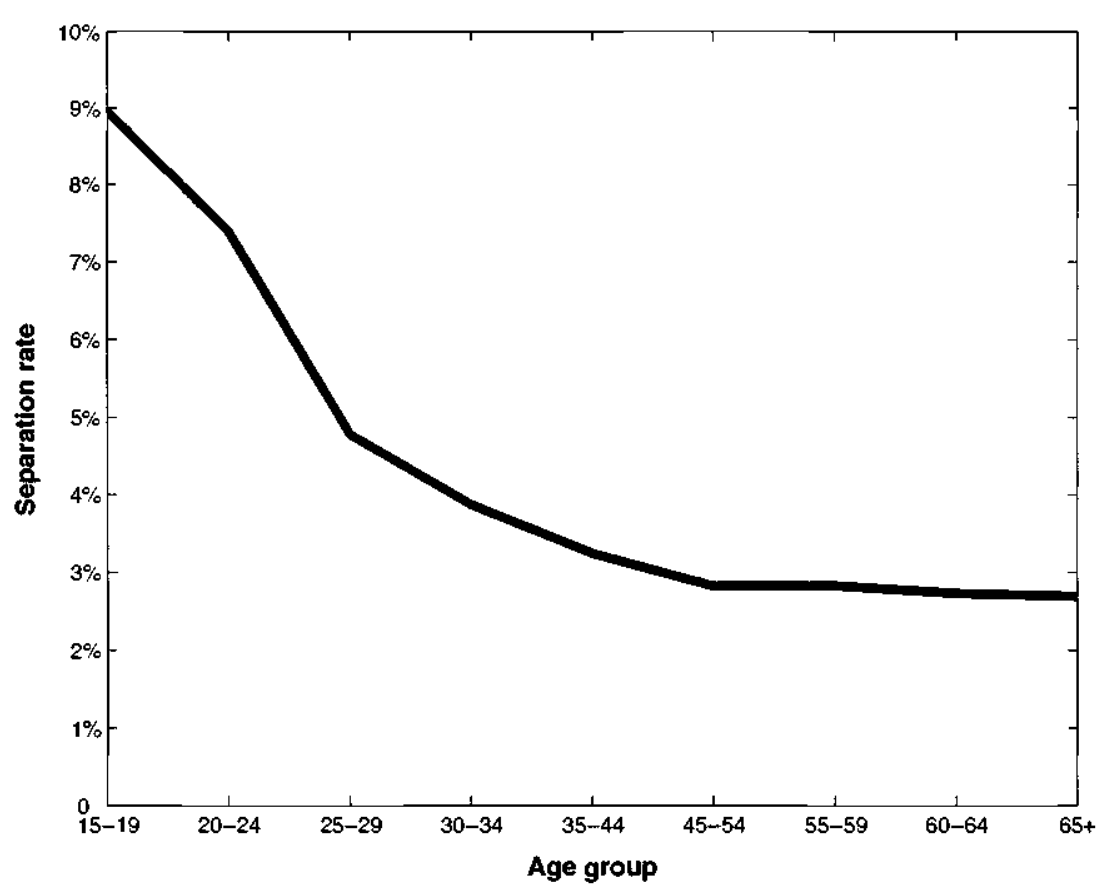

Figure 3

Monthly separation rate by age conditional on staying in the labor force

have less experience and lower tenure, on average, than their older counterparts. This experience includes knowledge about a particular firm, industry, or occupation, but it also includes knowledge about the worker's own ability or fit.

One way to demonstrate this lower level of specific human capital is to look at labor-market mobility by age. Figure 3 plots the monthly separation rate by age, conditional on staying in the labor force, using data from the Basic Monthly CPS between 1994 and 2003. It is clear that younger workers have much higher mobility levels than older workers do, even when conditioning on remaining in the labor force, i.e., disregarding the fact that younger workers are more likely to move in and out of the labor force.

\subsection{Looking for a Good Match when Young}

In this section, I sketch a model that relies on differences in a particular notion of specific human capital-differences in the knowledge about 
own ability/fit-to explain the higher response of young workers to business-cycle shocks. ${ }^{9}$ Its primary goal is to demonstrate, at least qualitatively, that differential amounts of specific human capital is a promising mechanism to consider. To keep the discussion simple, I abstract from the other channels considered in the GRRW model: the agents in the model are infinitely lived (no time-horizon chanrel), face no retirement (no time-to-retirement channel), have the same potential productivity regardless of age (no life-cycle-profile channel), and are risk-neutral (no asset-market channel since there is no precautionary savings motive).

\subsubsection{The Environment}

Consider the following extension of the model of Mortensen and Pissarides (1994). There is a unit mass of workers of two types, half of them round and half of them square. ${ }^{10}$ Workers are risk-neutral and discount future income at rate $r$. New workers are born and enter the labor market at rate $\sigma$, which is also the Poisson arrival rate of death, so that the size of the population remains constant over time. Newly born workers start out unemployed and do not know their type, although they know that they have probability one-half of being round and probability one-half of being square.

There are two labor markets: one for round people and one for square people. If a round person is matched in the round market, she produces $p x$; if a square person is matched in the round market, she produces $\varphi p x$, where $\varphi<1$. Here, $p$ is aggregate productivity, while $x$ is the idiosyncratic productivity of the match, the evolution of which is discussed below. If a square person is matched in the square market, she produces $p x$; if a round person is matched in the square market, she produces $\varphi p x$. Unemployed workers enjoy a flow utility of $b$.

There is a large measure of potential firms who are risk-neutral and have the same discount rate $r$. These firms can open a vacancy in either market and keep the vacancy open at a flow cost of $c$. Firms with a vacancy do not see, prior to matching, whether a worker is round or square. There is a single matching function in each market with the usual properties. Once a worker and a firm are matched, the type of the worker is revealed. The idiosyncratic productivity $x$ takes on its highest value of 1 when the worker and the firm match. While matched, new realizations of $x$ arrive at rate $\delta$ and are drawn from distribution $F:[0,1] \rightarrow[0,1]$. A worker and a firm can separate at any 
point in time and will generally choose to do so when the idiosyncratic productivity is low. Finally, wages are determined by Nash bargaining.

\subsubsection{Equilibrium}

It is straightforward to show that, in the steady-state equilibrium of this model for a given level of aggregate productivity, half of new workers are lucky and enter the market where they are well matched (i.e., they enter the market of their own type). They learn their type during their first employment spell and never switch from that market again. The other half of new workers are unlucky and enter the market where they are badly matched. They go through one employment spell, learn their type and the fact that they are better matched in the other market, switch to the market where they are well matched, and stay there until they die. It can also be shown that there is a distinct reservation productivity of a match depending on whether the worker is well-matched or not: $R_{\text {well }}<R_{\text {badly. }}$. In other words, matches that find out that they are badly matched do not end their relationship immediately since they find it beneficial to take advantage of their high idiosyncratic productivity. They are more stringent, however, about the level of idiosyncratic productivity required to continue the relationship since they know that the worker will be better matched in the other market once the relationship dissolves.

\subsubsection{Comparative Statics}

It is well known that, due to the high job finding rate that these type of models are generally calibrated to, analyzing a full dynamic stochastic version of the model with an explicit stochastic process for aggregate productivity gives results similar to analyzing the comparative static responses to changes in aggregate productivity. For the sake of simplicity then, I resort to the latter. It is easy to show that, just as in the standard Mortensen-Pissarides model, a decrease in the aggregate productivity $p$ gives rise to an increase in the reservation productivities. For a uniform distribution, the increase in the reservation productivity is higher for badly matched workers than it is for well-matched workers. Hence, the impact of a negative shock is larger on the destruction margin for badly matched workers than for well-matched workers. Since badly matched workers are disproportionately young, this means that the impact of a negative shock is larger on young 
workers. The mechanism of the model thus works in the right direction for explaining the larger response of the hours of the young to aggregate shocks.

\subsubsection{Simulation Results}

To demonstrate the above claim, I simulate the above economy and study the response of the hours of the different age groups to aggregate shocks. In particular, I use the following approximations. I assume that aggregate productivity follows a two-state Markov process. Instead of trying to determine the history-dependent optimal policies of the workers, I approximate their optimal policies by the steadystate optimal policies corresponding to the two levels of aggregate productivity. ${ }^{11}$

In Figure 4, I report statistics that correspond to the statistics constructed using the actual data in Figure 1. In particular, I report the share in total hours in the peak year and the share in the drop in total hours during the downturn for each age group. As can be seen, this

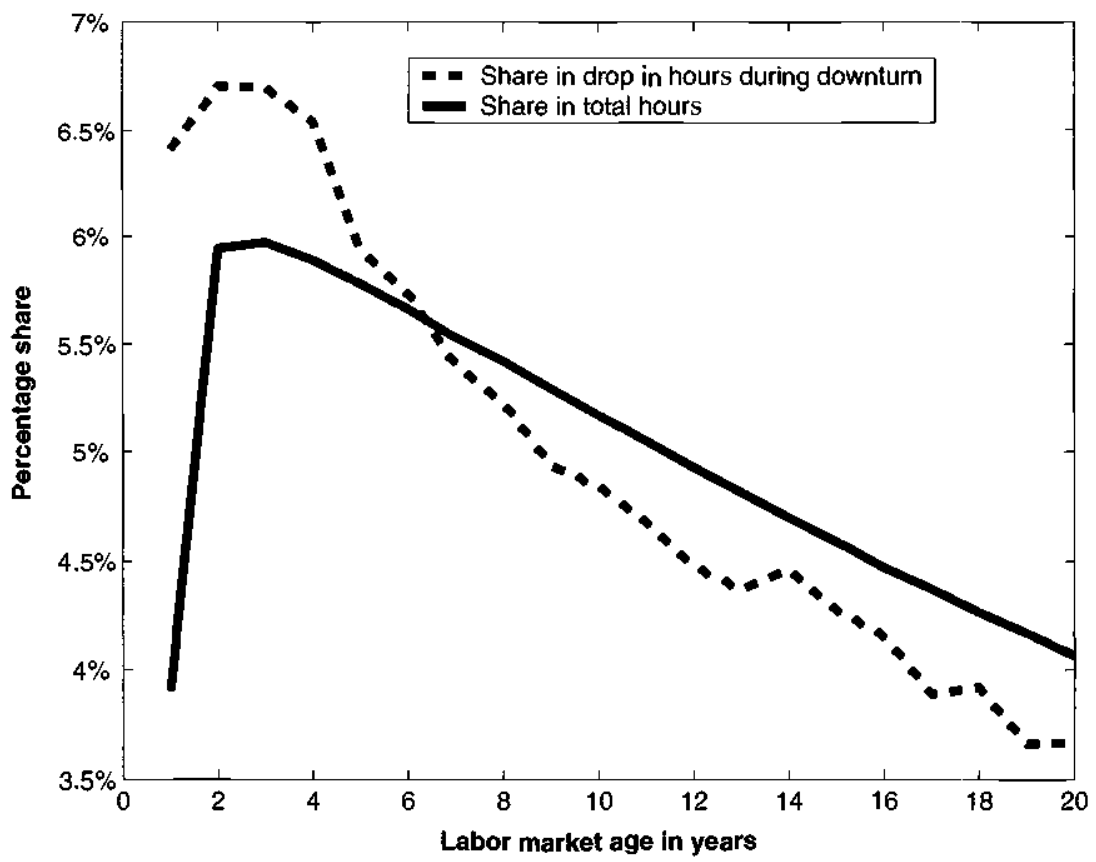

Figure 4

Model simulated share by age in total hours compared to model simulated share in drop in total hours during downturns 
model can qualitatively generate the main pattern in the data, namely, that young workers are more responsive to business-cycle shocks than are older workers. In other words, in the model, the burden of a downturn falls disproportionately on the young, just as in the data.

Since the model is one that features bilaterally efficient separations, it is not possible to distinguish between quits and layoffs. The results regarding cyclical variation can be understood, however, both from the firm's and from the worker's perspective. From the firm's perspective, during a boom, a firm is willing to employ even relatively unproductive and relatively poorly matched workers. During a recession, however, a firm becomes more stringent, and separates from workers who are relatively unproductive or are relatively poorly matched. Being relatively unproductive is a risk that all workers face, while the risk of being poorly matched falls on young workers. Hence, young workers face larger risk of separation during a recession. From a worker's perspective, during a boom, she is willing to work even in relatively unproductive jobs and in relatively poor matches since the opportunity cost of searching for a more productive job or a better match is high. During a recession, however, the opportunity cost of searching for a better match becomes lower. If a worker is relatively unproductive or badly matched, she separates and starts looking for a more productive match. Again, being badly matched is a risk that only young workers face; hence, they have larger separation rates in a recession.

\section{Conclusion}

The work of GRRW directs attention to a new and very exciting avenue of research regarding the heterogeneous labor-market impact of business-cycle shocks. They focus on heterogeneity in age, which, together with education, seems to be the most important dimension along which workers differ in their response to business-cycle shocks. While much work remains to be done, the work of GRRW demonstrates some of the mechanisms that could result in differing businesscycle responses across the life cycle.

Understanding demographic heterogeneity over the business cycle is relevant for several reasons. As the authors point out, the heterogeneous impact of business-cycle shocks is an important testing ground for theories of fluctuations. There are other reasons beyond methodological ones. For example, political-economy considerations implied by demographic heterogeneity could be crucial for understanding 
stabilization policies. Also, labor-market heterogeneity could have important consequences for economists' understanding of the cost of business cycles. In particular, if business-cycle shocks have larger and potentially lasting effects on the labor-market performance of young workers, this could significantly increase macroeconomists' estimates of the costs of business cycles. Overall, demographic heterogeneity in the labor-market response to aggregate shocks is something that is long overdue in arriving on the research agenda of macro-labor economists.

\section{Notes}

1. See the appendix in Section 9 of their paper for a more detailed explanation of the measure used and a motivation for its use.

2. The five downturns distinguishable in the annual data are 1970 to 1971,1974 to 1975 , 1981 to 1983,1990 to 1991 , and 2001 to 2002 , corresponding to the recessions beginning in December 1969, November 1973, January 1980, July 1990, and March 2001, respectively.

3. Plotting them separately for each downturn gives very similar patterns.

4. The cleanest way to disentangle this channel from the time-horizon channel is to consider an infinitely lived agent who can work only for the first $T_{R}$ periods of her life and is then forced to retire and receive a fixed endowment in all subsequent periods. The numerical exercise in Section 6.2 of the paper maintains the assumption of finite lives, meaning that the results are influenced both by the time-horizon and the time-toretirement channel.

5. This can be established more formally by log-linearizing the optimality conditions characterizing the decision problem of the worker around the steady state, which I omit for the sake of brevity, but which is available on request.

6. In light of the importance of the ratio of home to market hours, one could question the calibration exercise: it calibrates to married households only, which presumably biases the hours figures substantially for young households. Young people also spend a large fraction of their time in education, something that does not appear in the model or the calibration.

7. This channel is present in the variable labor version of the Krusell and Smith (1998) model presented in the appendix of their paper.

8. This comparison is made somewhat more difficult because Rios-Rull (1996) treated workers between 45 and 64 as one age group, while GRRW break them into two age groups. The primary effect of this difference is to make the impact of the time to retirement channel even more clear.

9. A more detailed exposition is available on request.

10. There is no conceptual difficulty in extending the model to more than two types.

11. In the standard Mortensen-Pissarides model, all decision variables are forwardlooking, and market tightness can adjust instantaneously, so it turns out that the optimal policies simply depend on the current aggregate state. In the variant of the model consid- 
ered here, this is no longer true because the distribution of well-matched and badly matched workers enters the state space of the firms.

\section{References}

Clark, K., and L. Summers. (1981). Demographic differences in cyclical employment variation. Journal of Human Resources 16:61-79.

Krusell, P., and A. Smith. (1998). Income and wealth heterogeneity in the macroeconomy. Journal of Political Economy 106(5):867-896.

Mortensen, D. T., and C. A. Pissarides. (1994). Job creation and job destruction in the theory of unemployment. Review of Economic Studies 61:397-415.

Nagypál, E. (2004). Unemployment differentials by skill: An explanation based on learning capital. Northwestern University. Working Paper.

Rios-Rull, V. (1996). Life-cycle economies and aggregate fluctuations. Review of Economic Studies 63:465-489. 


\section{Comment}

Robert Shimer

University of Chicago and

NBER

\section{Introduction}

This is an ambitious paper. The authors extend the standard real business-cycle model in two directions. First, they allow for both market production and home production, as in Benhabib, Rogerson, and Wright (1991). Second, they allow for overlapping generations of finitely lived agents, as in Rios-Rull (1996). They then compute the aggregate implications of the overlapping generations model for cyclical fluctuations, focusing on the relative volatility of market hours (the number of hours that the representative agent spends working in the market sector) and market output (the output that she produces in the market sector). The main question they ask is, Can this generalization of the real business cycle model explain the observed differentials in the cyclical fluctuations in hours across age groups in the United States? I will use most of my discussion to address this question, but an initial digression is useful.

\section{Representative Agent Model}

The representative agent model which the authors develop in Section 2 performs remarkably well. Depending on the intertemporal elasticity of labor supply $1 /(\gamma-1)$ and the elasticity of substitution between home and market goods $1 /(1-\xi)$, the authors can easily match the relative volatility of market hours and market output (see their Table 2). ${ }^{1}$ Therefore, a critical question is, Which values of these parameters are reasonable?

A well-established microeconomics literature starting with MaCurdy (1981) concludes from the life-cycle behavior of wages and hours worked in the market that an appropriate value for $\gamma$ is close to infin- 
ity, at least for men, but recent work has questioned that finding. For example, Keane and lmai (2004) argue that MaCurdy and followers neglect an important component of the compensation of younger workers, human capital accumulated at work. After correcting for this, they find that the intertemporal elasticity is close to 4 ; i.e., $\gamma$ is approximately 1.25. More to the point of this paper, Rupert, Rogerson, and Wright (2000) conclude that hours worked at home is an important omitted variable in MaCurdy-type regressions and show that including home work raises the estimated value of $\gamma$ considerably. Both of these arguments seem quite convincing, and so values of $\gamma$ not much larger than 1 are plausible.

There is much less evidence on the parameter $\xi$, that is, on the elasticity of substitution between home and market goods, although this parameter is also critical to the performance of the model. If home and market goods are strong complements, a decrease in market productivity induces workers to reduce the time they spend producing the complementary home goods, further reducing the cyclical fluctuations in market hours. The introduction of home goods amplifies the cyclical fluctuations in market hours only if the elasticity of substitution exceeds 1 . So what is a reasonable value of $\xi$ ? To my knowledge, only two papers have tackled this question. McGrattan, Rogerson, and Wright (1997) pin down $\xi$ using macro data and show that the model requires a high elasticity of substitution $1 /(1-\xi)$ to match the behavior of important aggregate variables, including market hours and consumption and home capital. But this is analogous to saying that we know that the intertemporal elasticity of substitution is high because we observe that market hours fluctuate a lot over the business cycle. It does not provide independent evidence on the empirical relevance of the particular model. One wants to use microeconomic evidence to calibrate macroeconomic models.

Rupert, Rogerson, and Wright (1995) provide the best such evidence, but their estimates are imprecise. They start by estimating a fairly complicated home production model, allowing for the possibility that home and market goods are imperfect substitutes, home and market hours are imperfect substitutes, and the production of home goods is a concave function of home hours. Perhaps not surprisingly, their estimates of this very general model are imprecise. Despite this, their point estimates suggest that the elasticity of substitution between home and market goods is economically indistinguishable from one for single men and marned couples, although it is larger for single women. This 
would seem to be a significant blow for the usefulness of the home production model in thinking about macroeconomics. But in footnote 13 in their paper, Rupert et al. impose that home and market hours are perfect substitutes and restrict the curvature of the home production function exogenously. They show that the estimates of $\xi$ for married couples range between 0.2 and 0.3 , somewhat less than the numbers that Gomme, Rogerson, Rupert, and Wright use in the current paper, but still significantly larger than zero. Based on this evidence, or lack of evidence, 1 think it is fair to say that the jury is still out on the true value of $\xi$, a viewpoint that seems to contrast with that of the authors.

\section{Life-Cycle Model: Cyclical Fluctuations}

The heart of this paper is the analysis of the behavior of employment volatility conditional on a worker's age. The authors use data from the March Current Population Survey (CPS) from 1962 to 2000 to document that the cyclical volatility of market hours is almost four times as high for teenagers as it is for prime-age workers. ${ }^{2}$ This volatility decreases monotonically until approximately age 50 , but is twice as high for workers over age 65 compared to workers age 45 to 64 . l've constructed a similar measure using times series for age-contingent employment-population ratios, constructed by the Bureau of Labor Statistics (BLS) from the basic (monthly) CPS from 1948 to 2003. The results are remarkably similar to those in the paper. lt is also worth noting that the relative volatility of different age groups is extremely stable over time.

Looking at this data and at the behavior of the aggregate model, the obvious hypothesis is that the aggregate model can satisfactorily explain the behavior of prime-age workers but does a poor job of explaining the behavior of younger and older workers. Of course, to test this hypothesis, it is necessary to write down a model in which workers of different ages interact. The overlapping generations model in Sections 4 and 5 is an obvious benchmark.

How well does the model perform? The authors claim that "the model's ability to account for fluctuations in [market] hours increases as we consider older age groups." At some level this is correct. In fact, the model predicts more hours volatility for workers age 55 to 64 than there is in the data. But this conclusion is misleading. The model 
ignores teenagers, the group with the greatest fluctuations in market hours. It imposes mandatory retirement at age 65 , and so it cannot hope to match the high volatility of market hours for the oldest workers. And for the age ranges that are considered in the model, the standard deviation of market hours is basically a decreasing function of age in the data and an increasing function of age in the model (Table 14). A more accurate conclusion is that the life-cycle model can explain virtually none of the age pattern of fluctuations in hours. If anything, the life-cycle model predicts the opposite of what is observed in the data.

It is not particularly surprising that the life-cycle model predicts little of the variation in the observed fluctuations in hours. As my discussion of the aggregate model should have made clear, there are two important determinants of the volatility of market hours: the intertemporal elasticity of labor supply $1 /(\gamma-1)$ and the elasticity of substitution between home and market goods $1 /(1-\xi)$. Although the authors allow different age workers to have different preferences over market goods, home goods, and leisure, and they allow different age workers to be endowed with labor that is more or less productive, they do not allow either of the elasticities to vary with age. I suppose this puts discipline on the theoretical exercise, but in light of the results, the obvious reconciliation between the model and data is to allow for the possibility that younger workers have a more elastic labor supply or are more willing to substitute between market and home goods than are prime-age workers.

Of course, one would like some direct microeconomic evidence in support of this hypothesis. It seems impossible to measure age variation in the intertemporal elasticity of labor supply using MaCurdy's (1981) methodology, so this might be untestable. But the authors could have easily extended Rupert, Rogerson, and Wright (1995) to examine how the elasticity of substitution between home and market goods varies with age. Introspection suggests to me that as people age and have children, they become less willing to substitute between any goods, in particular market and home goods, a pattern that may help to reconcile the model and data. ${ }^{3}$ Conversely, if the data do not show differential elasticities of substitution, I would again use the authors' words against them: "In looking for alternative theories to better account for aggregate labor market fluctuations, attention should be directed toward features that specifically affect individuals during the 
first half of their life." If the elasticity of substitution is the same over the life cycle, attention is best diverted away from home production models.

\section{Life-Cycle Model: Secular Trends}

There are some very interesting facts lurking in the shadows of this paper, in the secular trends in market hours. Although the number of hours worked per adult has not shown any trend in the United States during the past 55 years, ${ }^{4}$ this is not true for particular age groups. Figure 1 shows that in 1948, the employment-population ratio for people over age 65 stood at over $26 \%$. This fell steadily until around 1990 , reaching as low as $10 \%$ before increasing slightly in the last fifteen years. The decline for older men has been even more dramatic. The same data indicate the opposite pattern for workers age 20 to 54 , a secular increase in employment due to a sharp increase in women's increased labor force participation partially offset by a moderate decline in employment for prime-age men. Of course, this is not news to at least one of these authors, who has written: "the number of average weekly hours of market work per person in the United States since World War II ... has been roughly constant; for various groups, however, it has shifted dramatically from males to females, from older people to younger people, and from single- to married-person households" (McGrattan and Rogerson, 1998).

Why does this matter for Gomme, Rogerson, Rupert, and Wright? I am not simply saying that they should have written about secular trends instead of business-cycle fluctuations because the trends are more interesting than the cycle. In fact, it is conceivable that the same forces that explain the differential cyclical fluctuations in employment are also important for understanding the differential secular trends. But the secular trends raise a major concern: How does one calibrate such a model? The authors write "as is standard, we follow the procedure of requiring that parameter values are such that the model's deterministic steady state matches the time series averages for several aggregate variables." But if the aggregate variables are trending over time, does that mean that the calibrated parameters must also trend over time? It seems they must, which casts doubt on the discipline of the calibration exercise.

Conversely, the secular trends contain a lot of information that the authors ignore. McGrattan and Rogerson (1998) claim that changes in 

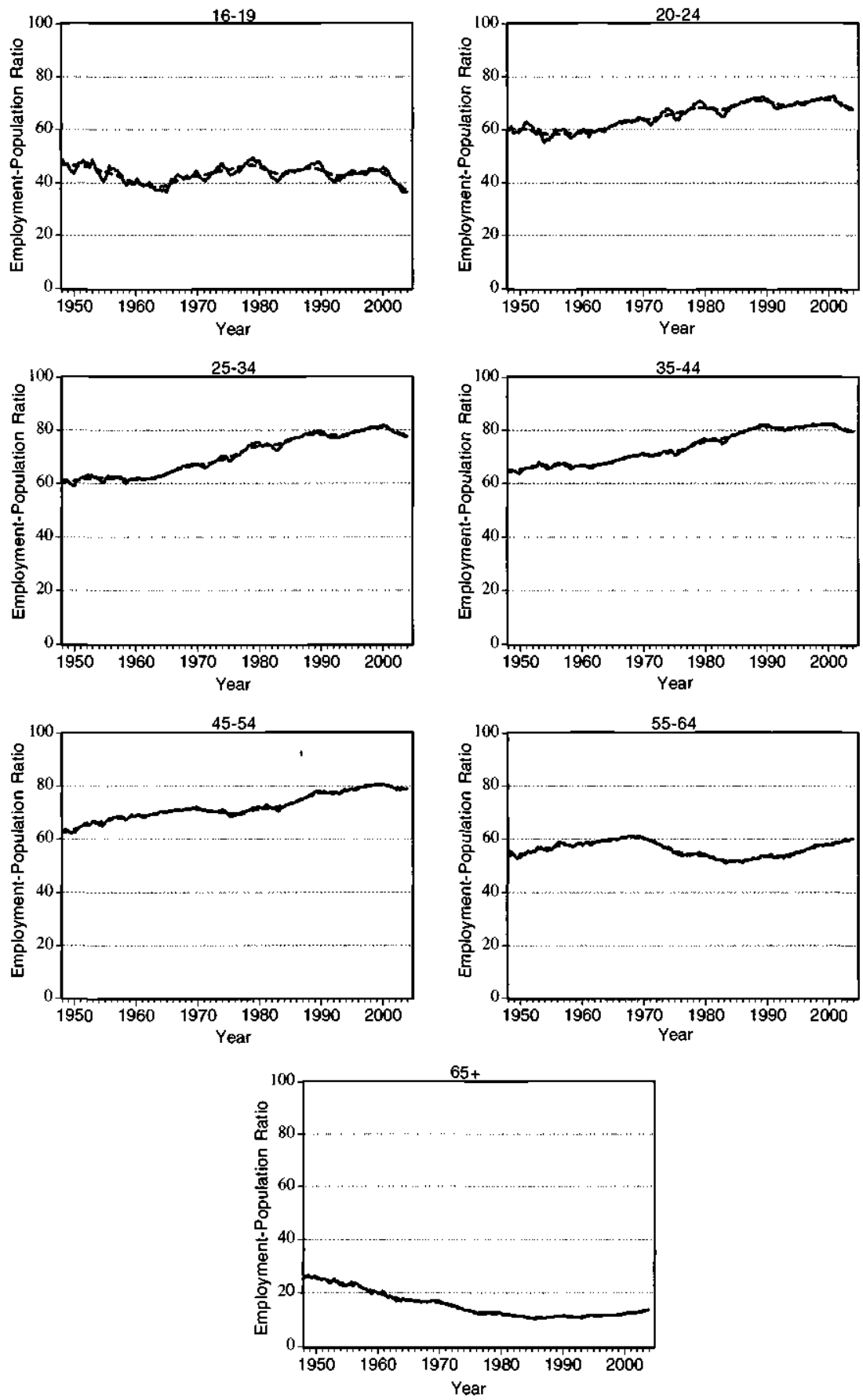

Figure 1

Employment-population ratio as a function of age, 1948-2003

The dashed line is an HP filter with smoothing parameter 1600 on quarterly data. The data were constructed by the Bureau of Labor Statistics from the CPS. 
social security benefits, in fertility rates, and in family structure are critical for understanding secular changes in the employment-population ratio. In light of these changes, should we be surprised that the crosssectional pattern of volatility is so stable over time? For example, if the cross-sectional pattern of volatility is due to different elasticities of substitution, then why did changes in fertility and family structure not alter the age-conditional elasticity of substitution and therefore rearrange the cross-sectional pattern of volatility? In other words, why is cyclical volatility so stable over time, even in the presence of the changes that induced large secular shifts in employment? Unfortunately, the paper does not answer this question.

\section{Conclusion}

Let me conclude by saying what I think we learn from this exercise. First, the authors make a convincing case that any model that purports to explain employment fluctuations must be able to explain why employment fluctuates more for younger workers and workers over the age of 65 than it does for prime-age workers. Second, they carefully describe and solve one particular model that, based on this criterion, cannot explain employment fluctuations: the real business-cycle model extended to allow for home production and overlapping generations. The next step is to explain what type of model can explain the crosssectional pattern of employment fluctuations. That is an interesting and important question that I suspect will continue to occupy researchers' attention for many years.

\section{Notes}

1. The authors do not ask whether the model can explain the absolute volatility of the variables. Presumably the answer depends on whether cyclical fluctuations in the Solow residual represent a primitive technology shock.

2. The authors measure the volatility of hours as the standard deviation of the detrended hours series for a particular age group projected on the detrended hours series for the overall population.

3 . Of course, this only makes the high volatility of hours for older workers more puzzling. Explaining this first requlres a serious model of the retirement decision.

4. I measure the employment-population ratio using the basic CPS and average hours worked for production workers using the Current Employment Statistics (CES). The product of these two numbers is a rough measure of average hours per person. Between 1964 (the first year when hours data are available) and 1983, the average person worked 
21.1 hours per week. Over the next 20-year period, this increased to 21.5 hours per week. There is no evidence of a secular trend in this variable.

\section{References}

Benhabib, Jess, Richard Rogerson, and Randall Wright. (1991). Homework in macroeconomics. Journal of Political Economy 99:1166-1187.

Keane, Michael, and Susumu Imai. (2004). Intertemporal lbor supply and human capital accumulation. International Economic Reziew 45:601-641.

MaCurdy, Thomas. (1981). An empirical model of labor supply in a life cycle setting. Journal of Political Economy 89:1059-1085.

McGrattan, Ellen, and Richard Rogerson. (1998). Changes in hours worked since 1950. Federal Reserve Bank of Minneapolis Quarterly Review 22:2-19.

McGrattan, Ellen, Richard Rogerson, and Randall Wright. (1997). An equilibrium model of the business cycle with household production and fiscal policy. International Economic Review 38:267-290.

Rios-Rull, Victor. (1996). Life-cycle economies and aggregate fluctuations. Review of Economic Studies 63:465-489.

Rupert, Peter, Richard Rogerson, and Randall Wright. (1995). Using panel data to estimate substitution elasticities in household production models. Economic Theory 6:179193.

Rupert, Peter, Richard Rogerson, and Randall Wright. (2000). Homework in labor economics: Household production and intertemporal substitution. Journal of Monetary Economics 46:557-579. 


\section{Discussion}

In response to the discussants' question about the objective and value added of the exercise presented in the paper, Richard Rogerson said that their work was rather a robustness exercise on some previous work, such as the one conducted by José-Víctor Ríos-Rull, and attempted a deeper analysis into what types of changes over the life cycle could account for the changes in volatility over the life cycle. Rogerson explained that Ríos-Rull's work was centered on whether aggregate fluctuations properties looked different in a life-cycle model than in an infinitely lived representative agent model, and looked at what happens to volatility over the life cycle but did not look into why it behaved the way it did. Rogerson said that in their work, they concluded that for reasonable parametrizations it was impossible to get the life-cycle pattern and that although they did not expect to obtain it, it was important to understand why. The fact that they obtained something that was flat over the life cycle meant that there was a failure of the model to generate the life cycle and this had very important implications concerning the type of modifications these models needed.

A number of participants expressed opinions regarding the relevance of incorporating frictions into the analysis. First, Rogerson responded to Éva Nagypál's comments by saying that even if their model did not include frictions, the way they were looking at the data might allow more precise identification of frictions and their effects on different age groups. John Leahy said that even if Rogerson had dismissed wage frictions as a potential explanation for their findings, maybe it would be interesting to look at seniority rules in firing decisions and what happened if that friction occurred. He wondered what the effects would be on decisions of who gets fired and who does not, or what types of jobs people got through the life cycle. Rogerson responded that they did not consider wage variability per se to be very important 
for explaining long-term relationships and they did not expect the wage to reflect the marginal value of production. Dave Backus said that what was useful about frictions was to use the same friction to explain more than one thing and suggested looking at the work of Romer and Gerome, which tried to explain consumption heterogeneity by age. In that work, young people who did not have a cushion of assets were pressed by the borrowing constraint and were more responsive on the consumption side; Backus wondered if this might have a similar effect on hours worked and be relevant to the authors' work. On this topic of the borrowing constraint, Éva Nagypál believed that it went the wrong way. Intuitively, she said, one might think that young workers, because of this constraint, had less opportunity to decrease their hours in a recession, but if one included durables and other kinds of goods, then the direction would be reversed. David Laibson believed that nominal wage rigidity mechanisms affected new workers more than those with more seniority because of the lack of joint surplus. $\mathrm{He}$ believed that high-frequency variations for new/young workers, the kind of dynamics shown in the data, would be appearing more and more often.

There were several interventions dealing with the differences along the life span. Steve Davis believed that the previous explanations were not enough because this was not just a cyclical phenomenon and suggested looking at the elasticity of the substitution parameter between market- and home-produced goods as a function of age. Rogerson admitted that in passing from an infinitely lived agent to the life cycle, they maintained the assumption of constant elasticities over the entire life span. He said that many of the labor supply elasticities came from estimations of prime-age individuals. Taking that into consideration, their model worked well for prime-age individuals but not for the wage history. Alessandra Fogli suggested looking at different family arrangements to understand different elasticities at different ages. Younger and older workers might rely more heavily on their primeage relatives who were less elastic. Rogerson said that in their overlapping generations model, they considered workers starting at age 20 and did not consider the 16 to 19 group precisely for the reasons mentioned by Fogli. The household structure in their model was based on a married couple, and people aged 16-19 were not considered to be in that kind of structure. He said that an open-ended question might be to what extent 16- to 19-year-olds were in different family structures and if that produced different outcomes. 
Mark Gertler brought attention to the fact that the authors were trying to address alternative explanations for a possible life-cycle pattern of volatility and this was innovative work. He also said that originally he had thought that the pattern found by the authors responded to the fact that most young workers could be in manufacturing. However, the authors' analysis showed that this did not seem to be the case and that the life-cycle pattern did exist for other sets of factors, such as sex or education. Gertler also agreed with Robert Shimer on the importance of the effect of demographics on volatility. He wondered if demographics could have a first-order effect on volatility the way that Shimer's work showed it did for the equilibrium unemployment rate. Gertler thought that getting at this would involve having effects and that it would need a structural model showing that demographics would have an aggregate effect on volatility. Rogerson responded by saying that Shimer mentioned the secular decline and that although it seemed interesting, it was difficult to incorporate it into their nodel because there was no consensus about what drives those secular trends. However, it would be possible to conduct an analysis like the one suggested by Shimer in terms of looking at two different pictures of the life-cycle profile, one for the 1950s and one for the 1990s. This could be a way to calibrate the model in two different ways and to see if there were different results. However, Rogerson believed the result would be similar to the one they had obtained and that it would be flat over the life cycle. He raised a deeper question, though, about the interactions between trends and cycles. He thought that sometimes there was confusion about what was a cycle and what was a trend and that such confusion could exaggerate fluctuations in some groups versus others.

Harald Uhlig was intrigued with the difference between the numbers for quarterly data and yearly data, which are what the authors used. He said that it was possible to use the Hodrick-Prescott (HP) smoothing parameter equal to 100 , but if they really wanted to replicate what was done with quarterly data, they would have to use a parameter of 7 . He thought that since they were using the parameter of 100 , maybe they were missing things that were happening at lower frequencies. He suggested that maybe hours fluctuate more quickly at higher frequencies, while unemployment fluctuates more at lower frequencies.

Finally, Jordi Gali expressed his reservations regarding the initial motivation given by the authors in terms of the inability of a standard representative-household model to generate sufficient volatility 
of hours with respect to output or productivity. He believed this was because the authors had chosen a model exclusively driven by technology shocks. With a model that allowed for sources of fluctuations other than technology shocks, there would be more volatility in hours than in either output or productivity. Rogerson acknowledged that their motivation came from a particular type of model and that other models would produce greater fluctuations. 


NBER Macroeconomics Annual 2004

edited by Mark Gertler and Kenneth Rogoff

The NBER Macroeconomics Anmual presents pioneering work in macroeconomics by leading academic researchers that is addressed to a broad audience of public policymakers as well as to the academic community. Each paper is followed by comments and discussion to give a more complete context for the views expressed. The 2004 edition features a range of papers aimed at providing coherent and informative answers to such important questions as the effect of federal government debt on interest rates; the stochastic dimension of the American economy; the role of technology as a source of economic fluctuations; and the interaction of capital flows, fiscal policy, and monetary policies in developing countries, emerging markets, and OECD countries.

Mark Gertler is Henry and Lucey Moses Professor of Economics, Chairman of the Economics Department, and Director of the C. V. Starr Center for Applied Economics at New York University. Kenneth Rogoff is Thomas D. Cabot Professor of Public Policy and Professor of Economics at Harvard University.

Contents

Graziela L. Kaminsky, Carmen M. Reinhart, and Carlos A. Végh

WHEN IT RAINS IT POURS: PROCYCLICAL CAPITAL FLOWS AND

MACROECONOMIC POLICIES

(comments by Gita Gopinath and Roberto Rigobon)

Eric M. Engen and R. Glenn Hubbard

FEDERAL GOVERNMENT DEBT AND INTEREST RATES

(comments by Jonathan A. Parker and Mattlew D. Shapiro)

Domenico Giannone, Lucrezia Reichlin, and Luca Sala

MONETARY POLICY IN REAL TIME

(comments by Harald Uhlig and Mark W. Watson)

Jordi Galí and Pau Rabanal

TECHNOLOGY SHOCKS AND AGGREGATE FLUCTUATIONS: HOW WELL DOES

THE RBC MODEL FTT POSTWAR U.S. DATA?

(comments by Elien R. McGrattan and Valerie Ramey)

David K. Backus, Bryan R. Routledge, and Stanley E. Zin

EXOTIC PREFERENCES FOR MACROECONOMISTS

(comments by Lars Peter Hansen and Ivan Werning)

Paul Gomme, Richard Rogerson, Peter Rupert, and Randall Wright

THE BUSINESS CYCLE AND THE LIFE CYCLE

(comments by Éva Nagypál and Robert Shimer)

The MIT Press

Massachusetts Institute of Technology

Cambridge, Massachusetts 02142

http://mitpress.mit.edu

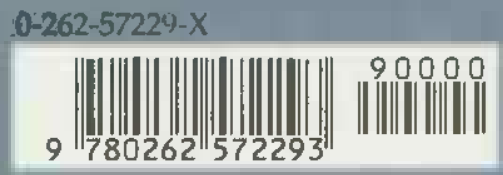

